\title{
A STUDY OF PURIFIED WOOD FIBERS AS A PAPER- MAKING MATERIAL
}

\author{
By Royal H. Rasch ${ }^{1}$
}

\section{ABSTRACT}

The characteristics of purified wood fibers and commercial papers prepared from these fibers are being investigated from the standpoint of chemical purity, color, durability, and permanence and compared with other typical papers and paper-making fibers.

The interest in the purified wood fibers lies not only in their value for highquality bond and writing papers of the grade hitherto made entirely from rag fibers or mixtures of rag and sulphite fibers but also very largely in their permanence qualities and thus the possibility of using them to supplant the higherpriced rag fibers in permanent record or other papers in which durability must be maintained over centuries.

Tests have been made on typical commercial grades of paper-making fibers, such as soda pulps, sulphite pulps, purified wood pulps, and rag half stocks. A thorough study was made of the physical properties of commercial papers made from fibers similar to the above. The effect of accelerated aging tests on the chemical and physical properties of these papers and paper-making fibers was determined in order to obtain information on the relative permanence of these materials.

The more important conclusions of this investigation follow. Accurate evaluations of the quality of papers or paper-making fibers must be based on specified performance tests. Fiber composition can not be taken as a criterion of the excellence of a paper. The manner in which the purified wood fibers and paper prepared from them react to the various tests for durability, permanence, color characteristics, etc., indicates that they are well adapted for conversion into high-quality bond and permanent record papers, which have hitherto been made exclusively from furnishes of high-grade rag half stock.

\section{CONTENTS}

II. Detailed outline of program

1. A study of paper-making fibers

2. A study of commercial papers _... 473

III. Description of methods used._. 473

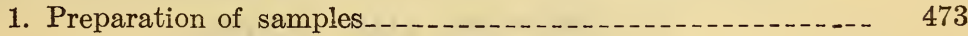

(a) Preliminary treatment of wood pulps and rag half stocks_... 473

(b) Preparation of cellulose materials for chemical testing -

1 Research associate of the Brown Co., Berlin, N. H.

$64338^{\circ}-29-9$ 
III. Description of methods used-Continued.

2. Test methods

(a) Chemical

content..... 474

(2) Copper number......... 474

(3) Pentosan content._._. 475

(4) Resin content.

(5) Ash content._.

(6) Acidity

(7) Glue

(b) Physical Commonly applied tests

(1) Commonly applied tests $(2)$ Color
(2)

(c) Accelerated aging tests

(1) Exposure to dry air at $100^{\circ} \mathrm{C}$

(2) Exposure to humidified air at $95^{\circ} \mathrm{C} \ldots \ldots . .-476$

(3) Exposure to rays from arc light_...-_-_-- 476

(4) Exposure to steam at atmospheric pressure_ $\quad 477$

IV. Description of samples studied._. 477

1. Paper-making fibers

2. Commercial papers

V. Results . .

1. Wood pulps and rag half stocks

(a) Chemical characteristics and reaction toward accelerated aging tests

(1) Alpha cellulose content.

(2) Copper number

(3) Pentosans

(4) Other tests

(b) Physical characteristics and reaction toward accelerated aging tests.........

(1) Color

(2) Microexamination of heat-treated fibers...-

2. Papers . .

(a) Durability and permanence characteristics

(1) General consideration of strength tests applied to papers

(2) Discussion of accelerated aging tests.....-

(3) Detailed discussion of results obtained with various papers.......

(b) Color characteristics

(c) Erasing quality of bond papers made from rag fibers and from purified wood fibers...... 503

(d) Alpha cellulose content_... 504

VI. Further work

\section{PURPOSE AND SCOPE}

The sulphite process of pulping wood is so recent a development in the history of paper making that, until a few years ago, very little definite information was available as to the actual aging qualities of 
papers prepared from this type of cellulose fiber. It was not known how long a carefully prepared sulphite paper could resist deterioration. Observations of authentic samples of these papers, after years of natural aging, have revealed conclusively that the ordinary grades of sulphite pulps are not adaptable to the manufacture of zarious types of papers in which the combined qualities of great strength, durability, and permanence are required. These observations, together with the well-known fact that some century-old books printed on rag papers are still in existence in a high state of preservation, strengthened the belief that for these special qualities, particularly permanence, a paper of high-grade rag fibers was essential and that wood fibers were by nature, and as a result of drastic methods used to pulp them, relatively weak and impermanent. Supporting this belief were the early views of cellulose chemists, who held that cellulose from wood was chemically distinct from cotton cellulose. With improved methods of isolating wood cellulose in pure form has grown the belief that it is identical with cotton cellulose in its chemical properties and subject to the same reactions.

Years of research have been devoted to the purification of wood fibers for various purposes, until at the present time wood fibers for paper making are being produced commercially by special processes which make them similar in many respects to paper-making rag fibers. Owing to these similarities, the purified wood fibers are superseding the higher priced rag fibers in many papers, even in those intended for use as permanent records. No data, however, have been available to the industry on the relative merits of this new fiber and other types of paper-making fibers. In response to a general demand for information of this kind, an investigation for the purpose of obtaining such data was undertaken by the National Bureau of Standards. The purpose of this paper is to present, in the form of a progress report, the information and data which have been obtained so far on relative qualities of purified wood fibers as compared to other typical papermaking fibers.

This paper will deal with a study of the more important chemical and physical properties of papers and paper-making fibers and the effect of accelerated aging tests on these properties. The investigation has thus far been limited to a study of representative commercial products.

\section{DETAILED OUTLINE OF PROGRAM}

The program of work was divided into two parts-a study of papermaking fibers and a study of commercial papers. The kinds of fibers included are only those used for fine writing papers. 


\section{A STUDY OF PAPER-MAKING FIBERS}

A preliminary study of purified wood fibers and other typical commercially prepared paper-making fibers entering into the manufacture of papers was first planned in order to determine the characteristics, principally chemical, of the different fibers and, if possible, to what extent these characteristics limit the permanence and other physical properties of papers. It was planned to obtain these samples from manufacturers of highest grade products, so that they would be representative of the best materials commercially obtainable at the present time. The following types of paper-making fibers were selected for the work, since they cover the range of fibers generally used for the manufacture of the better grades of papers:

Cotton rag half stock: ${ }^{2}$

From new rags.

From used rags.

Wood pulps:

Purified wood pulps.

Sulphite pulps.

Soda pulps.

Their wide variations in chemical purity and in the chemical nature of the impurities they contain offer a ready means of studying the relative effects of the different impurities on the various

${ }^{2}$ A brief description of the various paper-making fibers and methods used in their preparation is given below. For a more comprehensive discussion the reader is referred to the various textbooks on pulp and paper-making practice.

Most rags as they arrive at the mill require a mechanical and chemical cleaning. In the case of new white rags the constituent fibers are harsh, due to the presence of naturally occurring resins and waxes, and, even though sufficiently clean, are not well suited for direct conversion into paper. Old rags contain various impurities, such as dirt, grease, and dye, which must be removed. The rags, which are first sorted, cut into small pieces, and dusted, are boiled under pressure with lime or caustic soda or a mixture of the two. The amount of these chemicals used, as well as the other conditions of the cooking operation, vary from mill to mill and according to the kind of rags. A fter cooking, the rags are washed with a large volume of water in a beater and are simultaneously broken up and brushed out. The beater consists of an oval trough and a revolving beater roll on which is a series of bronze or steel blades engaging similar blades in the bottom of the trough. A means is provided for withdrawing the wash water as fast as fresh water is added. The rags are more or less discolored and require a bleaching treatment to bring them to the desired whiteness. For this purpose 1 to 5 per cent of calcium hypochlorite is used, depending upon the quality of rags. The final washed stock is technically termed "half stock" or "half stuff."

In the sulphite process wood chips are digested under pressure with a solution of bisulphites of alkaline earth metals (chiefly calcium) containing free sulphurous acid. The undesirable.lignin compounds as well as a large portion of the resinous materials and sugars are broken down, while the cellulose itself remains relatively unattacked. In subsequent washing and screening operations the soluble reaction products, dirt and coarse fragments, are removed. The desired whiteness of fiber is obtained by bleaching with calcium hypochlorite and finally washing. This material is referred to as "bleached sulphite pulp."

The soda process depends upon the fact that the various undesirable impurities associated with cellulose in wood are very soluble in hot caustic soda solutions. Chips of the wood are cooked in digesters under pressure with the alkali, and the resultant fiber is washed and bleached in much the same manner as in the sulphite process. The final product is termed "bleached soda pulp."

For an idea of the methods employed in the manufacture of purified wood fibers the reader is referred to a bibliography of patents on the subject: Manufacture of High Alpha Cellulose, by Joseph Rossman, Paper Trade J., 86, No. 15, p. 206; Apr. 12, 1928; also, Production of Pulp with High Alpha Cellulose, Paper Trade J., 85, No. 8, p. 75; Aug. 25, 1927. In general, fibers of this type are prepared by digesting wood pulps, manufactured by the usual pulping processes, in alkaline media to remove the remaining undesirable noncellulosic materials, as well as any modified celluloses that were formed. 
properties of the cellulose fibers with which they are associated and, consequently, of the papers into which they are converted.

It was proposed to make the commonly applied determinations, such as alpha cellulose content, copper number, pentosan content, resin content, and ash content; also, to determine the color characteristics of the fibers and their viscosity in cupra-ammonium solution. Since aging is known to have a marked effect on the chemical as well as physical properties of cellulose products, the more significant of the above tests were to be repeated on samples which had been subjected to accelerated aging tests.

\section{A STUDY OF COMMERCIAL PAPERS}

Next in the program of work was included a study of purified wood-fiber papers and various other types of high-grade commercial papers prepared from fibers similar to those outlined above, under 1. Included in this comparison were not only the applicable tests usually made on the paper-making fibers, but also all the commonly applied strength tests, as well as an examination of the papers for fiber composition, acidity, and for the kind and amount of sizing materials present. It was planned to make a thorough study of the probable degree of permanence of the different papers as measured by the extent to which their various chemical and physical properties resist the effects of heat, light, and moisture.

\section{DESCRIPTION OF METHODS USED}

\section{PREPARATION OF SAMPLES}

(a) PRELIMINARY TREATMENT OF WOOD PULPS AND RAG HALF STOCKS

In order to insure a high degree of uniformity in the method of handling samples, immediately upon being received they were all thoroughly mixed, slushed with water, and converted into 10 by 12 inch sheets with the laboratory hand sheet mold. ${ }^{3}$ Sufficient stock, made into a uniform suspension with water, was taken to give sheets weighing about $40 \mathrm{~g}$ bone dry. The sheets were pressed between clean felts, after which they were allowed to dry at room temperature and then carefully stored for future use.

In measuring color characteristics of fibers it was found more convenient to use thinner sheets, and for this purpose sheets weighing $10 \mathrm{~g}$ were made up.

(b) PREPARATION OF CELLULOSE MATERIALS FOR CHEMICAL TESTING

Papers, as well as wood pulps and rag half stocks, were reduced to a fibrous form before being subjected to the various chemical tests.

\footnotetext{
${ }^{8}$ Shaw, M. B., and Bicking, G. W., Paper Trade J., 79, No. 21, p. 51; Nov. 20, 1924.
} 
A discussion of the reasons for using material in this form, as well as a description of the apparatus employed, is given later on.

\section{TEST METHODS}

(a) CHEMICAL

(1) Alpha Cellulose Content.-By the so-called alpha cellulose content of a cellulosic material is meant the percentage of ash-free material resisting the action of sodium hydroxide of mercerizing strength. The method has been used to a great extent in the viscose industry as an aid to the determination of the suitability of pulps for the manufacture of rayon and to a lesser extent in the paper industry as a means of judging the chemical purity of paper-making fibers. It has become recognized that there is a relationship between the paper-making qualities of a given material and its content of caustic-resistant cellulose, and as a result more and more importance is being attached to this method. In this investigation considerable time has been devoted to this phase of the study, and a number of methods and modifications has been considered. The method as finally adopted is given below in detail.

Weigh out accurately $5 \mathrm{~g}$ of the air-dry disintegrated sample into a $400 \mathrm{ml}$ beaker. Add $50 \mathrm{ml}$ of an 18 per cent sodium hydroxide solution (1.200 specific gravity) at $20^{\circ} \mathrm{C}$. Let stand one or two minutes until pulp has absorbed caustic. Macerate well with a flattened glass rod and add another $50 \mathrm{ml}$ portion of caustic. Again macerate and allow to stand one-half hour from time caustic was first added, the temperature being held at $20^{\circ} \mathrm{C}$. Fill the beaker with distilled water at exactly $20^{\circ} \mathrm{C}$. and filter through a fine mercerized cotton cloth on a Buchner funnel. Return the filtrate through the pad of fibers and wash carefully with 1 liter of water at $20^{\circ} \mathrm{C}$. Remove the filtrate and save for the beta-cellulose determination. Wash the pad with $100 \mathrm{ml}$ of 20 per cent acetic acid and finally with 1 liter of boiling distilled water. Place pad in drying oven, and when fairly dry remove cloth filter, carefully scraping off with a spatula any adhering fibers. Transfer the removed fibers to a weighing bottle. Dry at $105^{\circ} \mathrm{C}$. to constant weight. Report the result as per cent alpha cellulose based on bone-dry ash-free fiber. Determine the moisture and ash on a separate sample.

(2) Copper Number.- The amount of copper reduced from a Fehling's solution by a given amount of cellulose material is termed the copper number of that material. This method is in wide use as a means of measuring the reducing power of the modified or degraded celluloses and other impurities present in the fiber and is generally considered a convenient means of predicting the probable extent to which a fiber will resist chemical or physical deterioration. The 
modified procedure as developed at the Bureau of Standards especially for determining the copper number of papers was used. ${ }^{4}$

(3) Pentosan Content.- Together with pentosans are included any other furfural-yielding substances that may be present, such as pectins in cotton. Oxycellulose is said to give slight yields of furfural on distillation with hydrochloric acid. The method used is similar to the usual ones involving the distillation of the sample with dilute hydrochloric acid, except that precipitation was accomplished by the use of thiobarbituric acid instead of phloroglucinol. ${ }^{5}$

(4) Resin Content.- The resin content as determined includes all the substances present which are extractable with acidulated alcohol, such as rosin used in sizing papers, naturally occurring resins, waxes, etc. The official procedure ${ }^{6}$ of the Technical Association of the Pulp and Paper Industry was followed.

(5) Ash Content.-The ash content is of importance, since it indicates the amounts of mineral residues left in the fibers and, in the case of papers, whether a mineral filler has been added. The official T. A. P. P. I. procedure was followed.

(6) AcIdity.-Acidity in paper is usually due to one or both of two causes-either to alum (which is added to the beater as a precipitant in rosin sizing and to the glue as a preservative for surface sizing) or to the acidic nature of decomposition products of cellulose itself. This decomposition, resulting in the development of acidity, is thought to be due to auto-oxidation resulting from the presence of alum or other inorganic acid materials or from the use of paper-making fibers containing oxycelluloses, lignin, or other impurities which affect their stability. Therefore, in any study of permanence, acidity is a factor of extreme importance. The method described by Hall has been tentatively adopted.7 Acidity number may be described as the number of cubic centimeters of 0.01 normal sodium hydroxide solution required to make the extract of $10 \mathrm{~g}$ of bone-dry disintegrated fiber neutral to phenolphthalein indicator.

(7) GluE.-The amount of glue used in surface-sized papers has a marked effect upon many of the strength qualities of the papers. The official T. A. P. P. I. method was used.

\section{(b) PHYSICAL}

(1) Commonly Applied Tests.-All the commonly applied, official T. A. P. P. I. paper-testing methods were used-as basis weight, thickness, bursting strength, folding endurance, tearing strength, and tensile strength.

\footnotetext{
4 Scribner, B. W., and Brode, W. R., A Modified Method for the Determination of the Copper Number of Paper, B. S. Tech. Paper No. 354; Sept. 24, 1927. Price, 5 cents. Superintendent of Documents, Washington, D. C.

${ }^{5}$ Directions given by Dox and Plaisance, J. Am. Chem. Soc., 38, p. 2156; 1916.

6 Copies of the official paper-testing methods of the Technical Association of the Pulp and Paper Industry may be obtained from the secretary at 18 East Forty-first Street, New York, N. Y.

7 Kohler, S., and Hall, G., Acidity in Paper, Paper Industry, 7, No. 7, pp. 1-5; October, 1925.
} 
(2) Color.-In classifying various papers and paper-making fibers according to their color characteristics, or, more especially, in comparing the stability of samples of these materials toward accelerated aging tests, ordinary methods of grading according to observations of the unaided eye are unsuited, since the variations are in many cases extremely slight. In this investigation, comparisons of color characteristics were based on measurements made with the Pfund colorimeter. $^{8}$

\section{(c) ACCELERATED AGING TEST}

(1) Exposure to Dry Air at $100^{\circ}$ C.-The exposure of samples being investigated for permanence qualities to elevated temperatures offers the most convenient of the available methods. This is one of the methods used at the Government Testing Institute at Stockholm in its investigation of permanence of papers and was considered by the workers there to closely simulate the effects of natural aging. ${ }^{9}$ As this test was conducted at the Bureau of Standards, a closed oven of the electric resistance type was employed. (See fig. 1.) A fan and air duct keep the air in constant, rapid circulation, thus maintaining a uniform temperature throughout the oven. A thermostat and relays were provided for controlling the temperature. The variations in temperature in an oven of this type are within $\pm 1^{\circ} \mathrm{C}$. Suitable racks are provided for suspending the samples.

(2) Exposure to Humidified Air at $95^{\circ}$ C.-This test was used to study the combined effects of heat and moisture on the various characteristics of papers. The test was conducted in the same oven described under (1). Beakers of water were placed in the oven in order to humidify the atmosphere.

(3) Exposure to Rays from Arc Light.-A study in the chemistry division of the Bureau of Standards of apparatus designed for finding the effect of light on materials has revealed the fact that a carbon arc lamp is well adapted to simulate the effects of natural sunlight and to give reproducible results when the conditions under which the samples are maintained during exposure are carefully controlled. For this purpose a cabinet has been provided in which the temperature and humidity may be kept at any desired point. (See figs. 2 and 3.) Top and sides (except exposure side) consist of triplicate window glass, while the exposure side consists of two thicknesses of a special glass, which is thinner and is said to be somewhat more transparent to the rays from the arc than is ordinary glass. A thermostat was provided for controlling the temperature, and a small fan keeps the air circulated and uniform in temperature

\footnotetext{
8 Pfund, A. H., A New Colorimeter for White Pigments and Some Results Obtained by Its Use, Am. Soc. for Testing Materials; June, 1920; also Lofton, R. E., A Measure of the Color Characteristics of White Papers, B. S. Tech. Paper No. 244; Aug. 28, 1923. Price, 5 cents, Superintendent of Documents. Washington, D. C.

${ }^{8}$ Hall, G., Permanence of Paper, Paper Trade J., 82, No. 14, pp. 185-191; A pr. 8, 1926
} 
B. S. Journal of Research, RP107

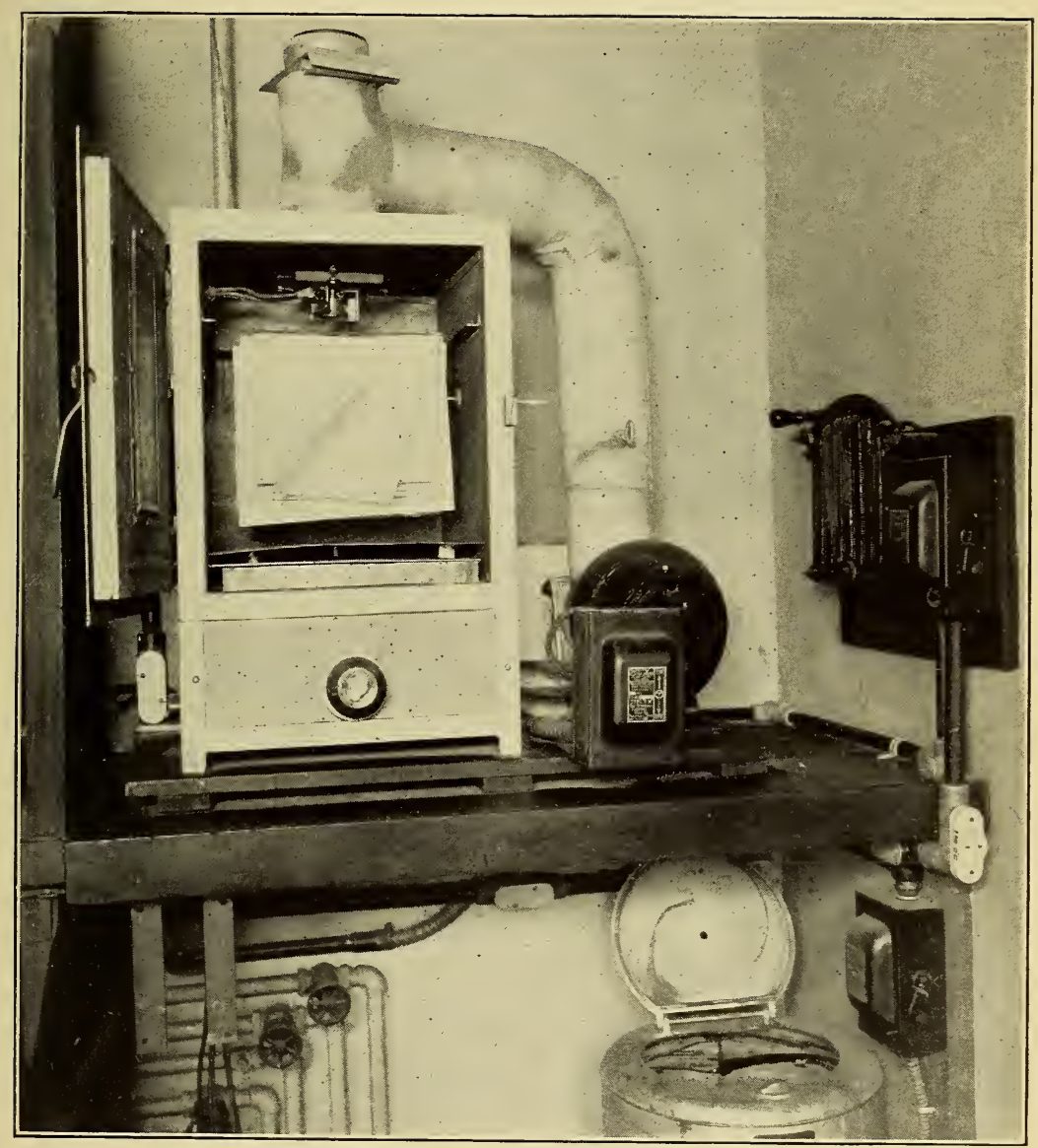

FIGURE 1.-Oven used for accelerated aging test 


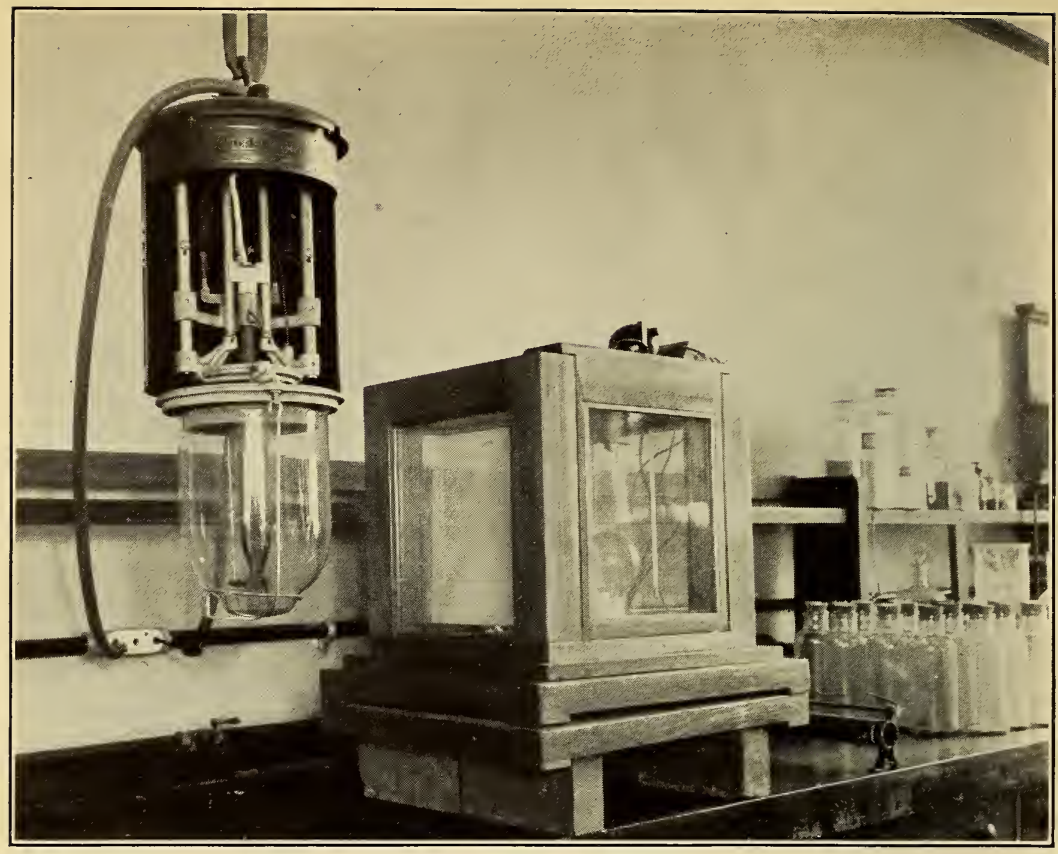

FIgURE 2.-Carbon-arc lamp and air-conditioning cabinet

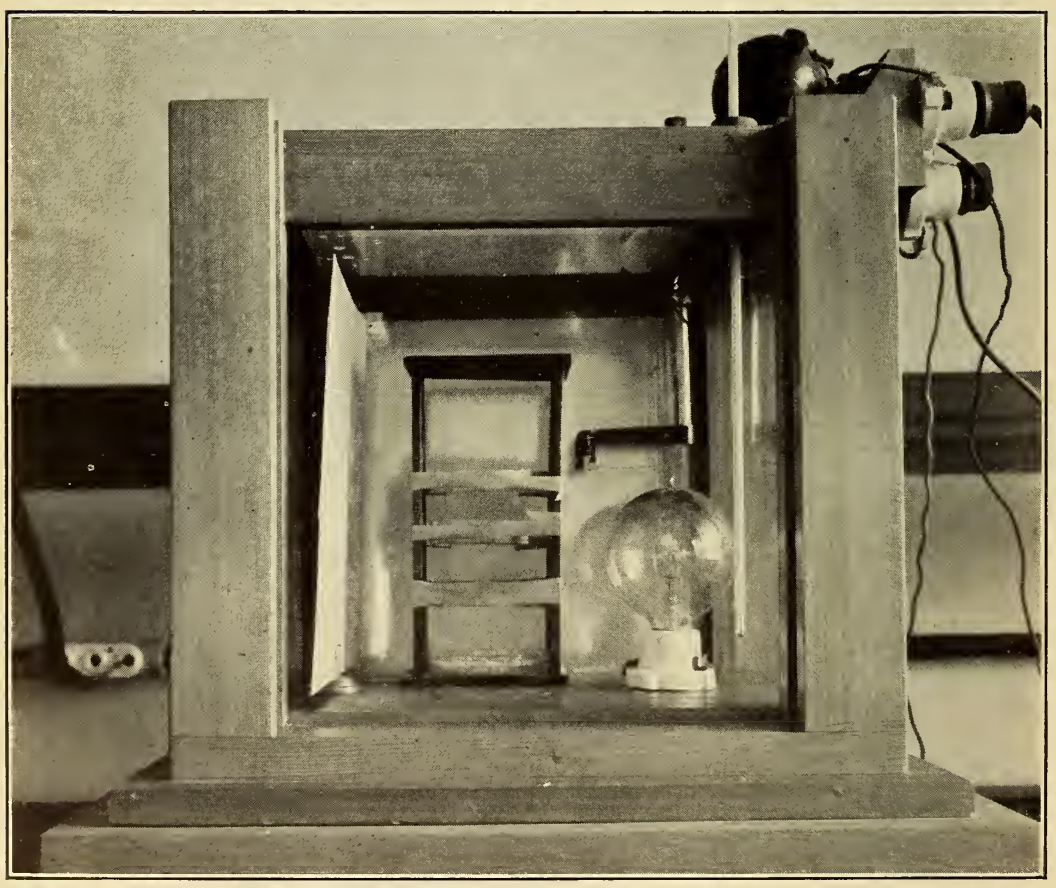

FIGURE 3.-Air-conditioning cabinet 
throughout the cabinet. The desired humidity is maintained by means of a saturated solution of the proper salt.

(4) Exposure to Steam at Atmospheric Pressure.-The use of steam as an accelerated aging test is based upon the observation that papers or pulp samples when exposed to the action of live steam show a marked tendency to revert in color. This test was conducted in a galvanized-iron chest well insulated with magnesia and provided with a cover containing a number of holes to permit the escape of steam. Live steam was injected through an inlet in the bottom of the chest. The samples to be exposed were suspended on suitable racks provided in the cabinet.

\section{DESCRIPTION OF SAMPLES STUDIED}

Following are tabulations of the samples studied, together with their code numbers and a brief description of each sample as given by the manufacturer who supplied it.

\section{PAPER-MAKING FIBERS}

The following samples of paper-making fibers represent products of 13 different manufacturers:

No.

1. Bleached sulphite pulp. Bond-paper grade.

2. 3. Purified wood pulp. Paper-making grade.

4. Bleached soda pulp. Book-paper grade.

5. Old colored rag half stock. "Twos and blues" grade.

6. New white rag half stock. "No. 1 unbleached" grade.

7. Bleached sulphite pulp Bond-paper grade.

8. Old white rag half stock. "No. 1 white" grade.

9. New white rag half stock. "New white shirt cuttings."

10. Old white rag half stock. "Extra No. 1 white" grade.

11. New white rag half stock. "Unbleached muslins."

12. New white rag half stock. "Mixture of 75 per cent new white shirt cuttings and 25 per cent bleached shoe cuttings."

13. Old white rag half stock. "Mixture of 50 per cent No. 1 white and 50 per cent No. 2 white cottons."

14. New white rag half stock. "New white shirt cuttings."

15. New colored rag half stock.

16. Old white rag half stock. "Old white cuttings."

17. Bleached sulphite pulp. Bond-paper grade.

18. Purified wood pulp. Special grade for esterification.

19. Bleached sulphite pulp. Special grade for esterification.

22. Bleached soda pulp. Book-paper grade.

23.

24. Bleached sulphite pulp. Bond-paper grade.

25.

26. Purified wood pulp. Paper-making grade. 
28. Purified wood pulp. Special grade for esterification.

29.)

30.

31. Purified wood pulp. Paper-making grade.
32.

\section{COMMERCIAL PAPERS}

\section{The following papers represent products of 12 different manu-} facturers:

No.

101. All-rag bond paper. Prepared from new rags; rosin ${ }^{10}$ and glue sized.11

102. All-rag bond paper. Prepared from new rags; rosin and glue sized.

103. Rag paper. Prepared from new rags. Contains a smail amount of sul104. phite fiber; rosin and glue sized.

105.

106. Purified wood fiber paper; rosin and glue sized.

107.

108. Sulphite writing paper; rosin sized.

109.)

110. Sulphite bond paper; rosin sized.

111. Bond paper prepared from a mixture of rag fiber and sulphite pulp; rosin sized.

112. Same paper as No. 111, but surface sized with glue.

113. All-rag bond paper. Prepared from new rags; rosin and glue sized.

114. All-rag bond paper. Prepared from new rags; rosin sized.

115.

116. Sulphite bond paper. Rosin sized.

117.

118. All-rag bond paper. Same as No. 114, but surface sized with glue.

119. All-rag bond paper. Prepared from new rags; rosin sized.

120. All-rag bond paper. Same as No. 119, but surface sized with glue.

121. All-rag waterleaf ${ }^{12}$ paper. Used for acetylation.

122. Purified wood-fiber paper. A waterleaf paper used for nitration.

123. Book paper. The beater furnish was 50 per cent soda pulp, 25 per cent sulphite pulp, and 25 per cent converted old papers; high clay content; rosin sized; high finish.

124. Book paper. Beater furnish similar to No. 123, but has lower clay content; bulkier and softer sheet than No. 123.

126. All-rag bond paper. Prepared from 60 per cent new white shirt cuttings and 40 per cent unbleached muslins; rosin and glue sized.

127. The same paper as No. 126 sampled before the glue-size tub.

10 Ordinary printing and book papers and sulphite bond papers are sized with rosin alone. This operation takes place in the beater. A suspension of free rosin in a solution of sodium resinate is added to the stock in the beater, and after it has been thoroughly incorporated with the fiber, aluminum sulphate is added to set the sizing material. The subsequent drying on the finishing end of the paper machine fuses the rosin particles and completes the efficiency of the sizing operation.

11 High-grade bond and record papers are "tub sized" or "surface sized" with glue. Glue imparts to papers many desirable qualities impossible to obtain by the use of rosin size alone; for example, an excellent writing surface, increased durability and resistance to wear, as well as certain intangible qualities of appearance, feel, etc. Papers of this type are practically always first rosin sized in the usual manner and then surface sized by passing the sheet through a solution of animal glue. In the best practice the gluetreated paper is loft dried; that is, it is suspended in a festoon arrangement in a special chamber where it is dried under carefully controlled conditions of temperature and humidity.

12 "Waterleaf" is a mill term signifying unsized paper. Such paper is usually of a very absorbent nature and unsuited for writing on or purposes where a degree of water resistance is required. 
B. S. Journal of Research, RP107

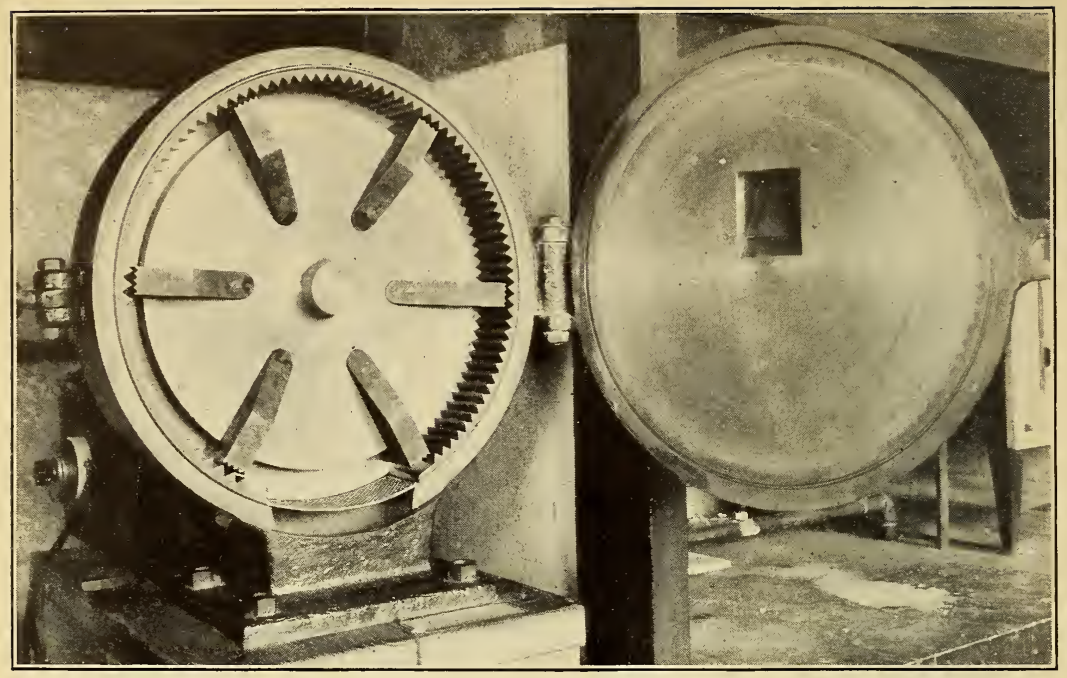

Figure 4.-Paper disintegrator

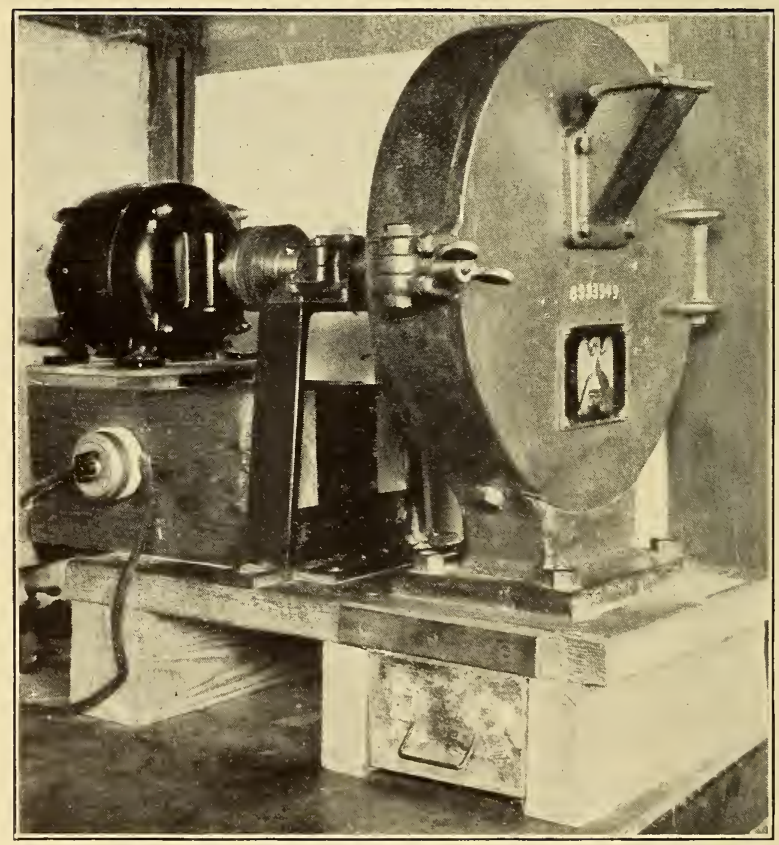

Figure 5.-Paper disintegrator 
128. All-rag bond paper. Prepared from 100 per cent unbleached muslins; rosin and glue sized.

129. The same paper as No. 128 sampled before the glue-size tub.

130. All-rag paper. Prepared from 100 per cent "No. 1 white old rags"; rosin and glue sized.

131. The same paper as No. 130 sampled before the glue-size tub.

132. Paper prepared from a mixture of rag fiber and sulphite pulp Rosin and glue sized.

133. The same paper as No. 132 sampled before the glue-size tub.

134. Sulphite bond paper. Rosin sized.

135. Sulphite writing paper. Rosin sized.

147. Book paper, magazine grade. The beater furnish for this paper was 87 per cent soda pulp and 13 per cent sulphite pulp; high clay content; rosin sized.

148. Coating paper. ${ }^{13}$ The beater furnish ${ }^{14}$ for this paper was 24 per cent sulphite pulp, 62 per cent purified wood fiber, and 14 per cent broke, ${ }^{15}$ low clay content; rosin sized.

152. Book paper. Rosin sized. The beater furnish for this paper was 70 per cent soda pulp and 30 per cent sulphite pulp; high clay content; rosin sized.

\section{RESULTS}

\section{WOOD PULPS AND RAG HALF STOCKS}

\section{(a) CHEMICAL CHARACTERISTICS AND REACTION TOWARD ACCELERATED AGING} TESTS

(1) Alpha Cellulose Content.-Most procedures for the determination of alpha cellulose specify that the material being tested, especially if it is a wood pulp, shall be in the form of squares of a given size and thickness. Ordinarily this procedure is quite satisfactory, but for the purposes of the present investigation it has been considered advisable to make this and other chemical tests, such as copper number and acidity, with material disintegrated in a special apparatus provided for that purpose. ${ }^{16}$ (See figs. 4 and 5.) It is very difficult to macerate papers, particularly sized and highly finished papers, with mercerizing caustic solution, and impossible to do so in a reproducible manner (even with waterleaf papers) unless the sizing material and formation of the sheet is broken up in such a way as to make the fibers available to the action of the caustic. The least objectionable method of accomplishing this result appears to be by the use of the disintegrator already referred to. In order to establish uniform methods of procedure in this work and to have a common basis for the comparison of alpha cellulose values obtained on papers and on paper-making fibers, it was considered desirable to convert the latter

13 Coating papers are those used as a base for enameled or coated papers.

14 This paper was found to contain 25 per cent deciduous wood fiber.

15 "Broke" is the trimmings and waste from the paper machine.

16 Hall, G., Permanence of Paper, Paper Trade J., 82, No. 14; pp. 185-191; A pr. 8, 1926; also, Scribner, B. W., and Brode, W R., A Modified Method for the Determination of the Copper Number of Paper, B. S. Tech. Paper No. 354; Sept. 24, 1927. Price, 5 cents, Superintendent of Documents, Washington, D. C. 
into the same disintegrated form before applying the alpha cellulose and other chemical tests. In obtaining comparative alpha cellulose values for different types of fibers there is another factor that requires consideration. Different materials in sheet form do not macerate with equal ease in mercerizing caustic, although this would appear to be essential where a direct comparison of this type is being made. For example, it was found that squares of purified wood fibers absorbed the caustic readily, forming a smooth, even suspension of wellseparated fibers, thus exposing a maximum of surface to the action of the caustic; on the other hand, the rag half stocks, more or less in the form of small bits of cloth, threads, and knots, could not be thoroughly pulped at all. Another difficulty encountered was that the soda pulps became extremely resistant to the penetration of caustic after the heat treatment. It was found, however, that all the above difficulties could be obviated by using disintegrated fiber. Table 1 summarizes the effects of grinding on different types of materials. Each value is a composite of results obtained on all available samples of a given type of material. It is clear that the alpha cellulose values obtained on disintegrated fibers are from 1 to 2 per cent lower than those obtained on materials in sheet form, and that this decrease is somewhat greater for rag half stocks than for wood pulps.

TABLE 1.-Effect of disintegration on alpha cellulose content of typical paper-making fibers

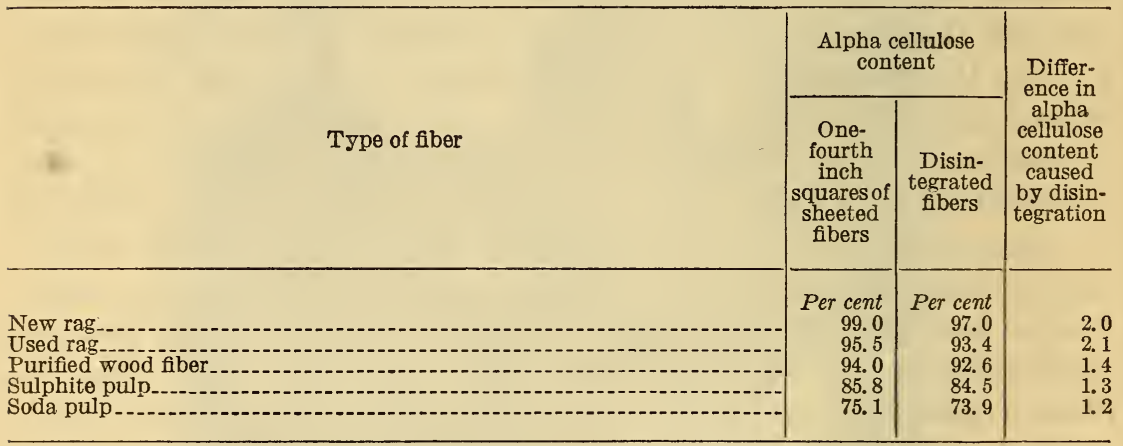

In Table 2 the alpha cellulose results obtained for individual samples of paper-making fibers are given, also results obtained with samples heated 72 hours at $100^{\circ} \mathrm{C}$. The effect of this artificial aging is expressed as the percentage of original alpha cellulose lost. 
TABLE 2.-Chemical'tests on various paper-making fibers

TESTS ON RAG HALF STOCKS

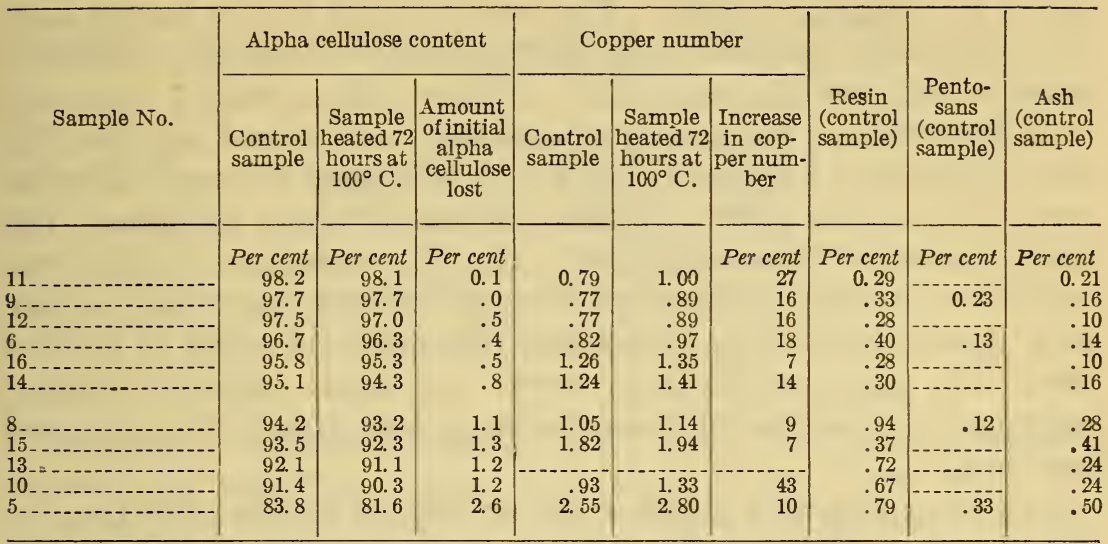

TESTS ON PURIFIED WOOD PULPS

\begin{tabular}{|c|c|c|c|c|c|c|c|c|c|}
\hline $\begin{array}{l}3 \\
3 \\
18 \\
28\end{array}$ & $\begin{array}{l}93.8 \\
93.2 \\
93.2 \\
93.1 \\
92.4\end{array}$ & $\begin{array}{l}93.6 \\
93.3 \\
92.7 \\
92.8 \\
92.5\end{array}$ & $\begin{array}{r}0.2 \\
1.1 \\
.5 \\
.3 \\
1.1\end{array}$ & 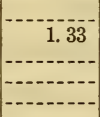 & 1.44 & 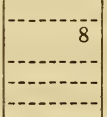 & $\begin{array}{r}0.29 \\
.20 \\
.32 \\
.31 \\
.27\end{array}$ & $\begin{array}{r}2.12 \\
\hdashline 3.32\end{array}$ & $\begin{array}{r}0.15 \\
.10 \\
.12 \\
.14 \\
.19\end{array}$ \\
\hline $\begin{array}{l}31 \\
26 \\
32 \\
29 \\
30\end{array}$ & $\begin{array}{l}92.4 \\
92.3 \\
91.9 \\
91.5 \\
91.5\end{array}$ & $\begin{array}{l}92.2 \\
92.5 \\
91.9 \\
91.2 \\
91.3\end{array}$ & $\begin{array}{r}.2 \\
1.2 \\
.0 \\
.3 \\
.2\end{array}$ & $\begin{array}{r}.89 \\
1.23 \\
.90 \\
.89 \\
.93\end{array}$ & $\begin{array}{r}1.00 \\
1.34 \\
.98 \\
1.02 \\
1.06\end{array}$ & $\begin{array}{r}12 \\
9 \\
9 \\
14 \\
14\end{array}$ & $\begin{array}{r}.32 \\
.38 \\
.25 \\
.27\end{array}$ & 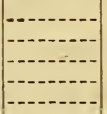 & $\begin{array}{l}.09 \\
.13 \\
.10 \\
.19 \\
.19\end{array}$ \\
\hline
\end{tabular}

TESTS ON SULPHITE PULPS

\begin{tabular}{|c|c|c|c|c|c|c|c|c|c|}
\hline 190 & $\begin{array}{l}86.5 \\
86.1 \\
85.3 \\
84.8\end{array}$ & $\begin{array}{r}85.1 \\
85.3 \\
83.2\end{array}$ & $\begin{array}{r}1.6 \\
.9 \\
1.9\end{array}$ & 3. 22 & $\begin{array}{l}3.18 \\
3.25\end{array}$ & $\begin{array}{c}\cdots \\
2\end{array}$ & $\begin{array}{r}0.77 \\
.81 \\
.49 \\
.63\end{array}$ & 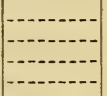 & $\begin{array}{r}0.22 \\
.16 \\
.19 \\
.15\end{array}$ \\
\hline $\begin{array}{l}7 \\
25 \\
24 \\
1\end{array}$ & $\begin{array}{l}84.1 \\
83.8 \\
83.2 \\
82.7\end{array}$ & $\begin{array}{l}83.0 \\
82.7 \\
81.9 \\
81.3\end{array}$ & $\begin{array}{l}1.3 \\
1.3 \\
1.6 \\
1.7\end{array}$ & $\begin{array}{r}3.32 \\
2.98 \\
3.29\end{array}$ & $\begin{array}{r}3.55 \\
-3.10 \\
3.45\end{array}$ & $\begin{array}{r}7 \\
4 \\
5\end{array}$ & $\begin{array}{l}.10 \\
.72 \\
.50 \\
.52\end{array}$ & $\begin{array}{r}3.86 \\
3.32\end{array}$ & $\begin{array}{l}.16 \\
.14 \\
.17 \\
.23\end{array}$ \\
\hline
\end{tabular}

TESTS ON SODA PULPS

\begin{tabular}{|c|c|c|c|c|c|c|c|c|c|}
\hline $\begin{array}{l}21 \\
4 \\
22\end{array}$ & $\begin{array}{l}78.9 \\
74.6 \\
68.1\end{array}$ & $\begin{array}{l}78.5 \\
73.5 \\
66.0\end{array}$ & $\begin{array}{l}0.5 \\
1.5 \\
3.1\end{array}$ & $\begin{array}{l}2.54 \\
3.71 \\
2.57\end{array}$ & $\begin{array}{l}2.58 \\
4.01 \\
2.96\end{array}$ & $\begin{array}{r}2 \\
8 \\
15\end{array}$ & $\begin{array}{r}0.72 \\
.89 \\
.45\end{array}$ & 12.12 & $\begin{array}{r}0.58 \\
.32 \\
.52\end{array}$ \\
\hline
\end{tabular}

1 Gain.

Although several different types of rag half stocks, widely different in their various properties, are included in this study, it is convenient to consider them together in one group. New, carefully bleached cotton cloth has an alpha cellulose content of very nearly 100 per cent; that is, it is practically pure cellulose. Therefore, the values obtained for the half stocks represent the extent to which the cellulose has been modified or degraded either in preliminary treatments or in the actual preparation of the half stock. New, white, unused rags require a 
much less drastic treatment in their preparation than colored or used rags, and therefore may be expected to have a much higher percentage of unchanged cellulose. The results reveal this to be the case. The half stocks prepared from new white shirt cuttings, unbleached muslins, and the like have alpha cellulose values ranging from 95.1 to 98.2 per cent; a half stock prepared from new colored rags (No. 15) had a value of 93.5 per cent; half stocks from good grades of old white rags contained from 91.4 to 95.8 per cent of alpha cellulose. The grade known as "twos and blues" (No. 5), one sample of which was available for study, is prepared from old colored rags which require very drastic cooking and bleaching treatments in order to convert them into paper-making half stock. Its alpha cellulose content is evidently a fairly accurate indication of how drastic this treatment has been.

It is evident from a glance at the column of results indicating the loss in alpha cellulose suffered by the various half stocks due to the heat treatment that the stability of these samples is dependent mainly upon the original alpha cellulose content. These results with half stocks lend themselves to interpretation more readily than those obtained with wood fibers because the caustic-soluble impurities present are of a less complex nature, consisting almost entirely of modified celluloses. These degradation products of the pure cellulose probably aid catalytically, in proportion to the amounts present and their chemical nature, to cause further oxidation of the remaining cellulose. The heat probably accelerates an oxidizing action, which, under normal aging conditions would take years. As the half stocks studied have a wide range of chemical purities, similarly do they present examples of great variations in stability toward artificial aging. New rag half stocks-that is, those of highest grade-are, in general, very stable to the effects of the heat treatment. It appears, however, that this is not necessarily the case, for sample No. 14, although prepared from new white rags, has an alpha cellulose content of but 95.1 per cent (low for this type of material) and is correspondingly less stable than others of this type. On the other hand, sample No. 16 gives evidences of having been carefully processed, since, although prepared from a grade of used rags, it has an alpha cellulose content of 95.8 per cent and loses but 0.5 per cent of this on being heated. To further illustrate the effects of oxycelluloses on the permanence qualities of cellulose fibers, samples of high-grade rag half stock were purposely overbleached with different amounts of calcium hypochlorite. The bleached samples were thoroughly washed to remove chemical residues, made into sheets on the laboratory hand mold, and then allowed to dry at room temperature. Alpha cellulose determinations were made on the original and the heat-treated samples. These values, which are given in Table 3 , indicate very clearly the damaging influence of oxycellulose 
on the stability of cellulose fibers. They further serve to show the importance of the alpha cellulose determination.

TABLE 3.-Effect of oxycellulose in overbleached rag half stock on permanence of alpha cellulose

\begin{tabular}{|c|c|c|c|}
\hline \multirow[b]{2}{*}{$\begin{array}{l}\text { Bleach } \\
\text { con- } \\
\text { sumed }\end{array}$} & \multicolumn{2}{|c|}{ Alpha cellulose content } & \multirow{2}{*}{$\begin{array}{c}\text { Decrease } \\
\text { in initial } \\
\text { alpha } \\
\text { cellulose } \\
\text { content }\end{array}$} \\
\hline & $\begin{array}{c}\text { Before } \\
\text { heating }\end{array}$ & $\begin{array}{c}\text { After } \\
\text { heating } \\
72 \text { hours } \\
\text { at } 100^{\circ} \mathrm{C} .\end{array}$ & \\
\hline $\begin{array}{c}\text { Per cent } \\
0 \\
1 \\
3\end{array}$ & $\begin{array}{c}\text { Per cent } \\
98.2 \\
95.5 \\
87.3\end{array}$ & $\begin{array}{c}\text { Per cent } \\
98.1 \\
94.4 \\
85.4\end{array}$ & $\begin{array}{c}\text { Per cent } \\
0.1 \\
1.2 \\
2.2\end{array}$ \\
\hline
\end{tabular}

It might be predicted that the wood fibers would react differently toward the accelerated aging tests than the rag fibers, since they contain impurities not present in the latter in any appreciable amounts. It could be reasonably assumed, for example, that the pentosans, which are present in wood fibers and almost entirely absent from rag fibers, would have a different effect on the stability of cellulose than would the oxycelluloses. Also, wood pulps contain some gamma cellulose (the caustic-soluble portion of a cellulose, which, in contradistinction to beta cellulose, is not precipitated by acid), which was found to be almost entirely absent in any of the various types of rag stocks. Lignins which occur in wood are probably not present in sufficient amounts, however, in any of the fibers here studied to influence the results obtained. In addition to the impurities distinct in nature from those present in rags, wood fibers also contain modified celluloses formed during the cooking and bleaching operations. It is not known how the modified celluloses in different types of wood fibers resemble in their chemical characteristics one another or those found in rag half stocks, but it appears that, regardless of source, they are exceedingly detrimental to the permanence of the fiber.

To determine the precise effect of the different impurities found in wood pulps on such qualities as permanence and to assign definite weights to them is obviously impossible except in an indirect way. It is possible, however, to study the combined effect of these impurities on the stability of the cellulose fibers with which they are associated. The purified wood fibers are all very stable in alpha cellulose content to a 72 -hour heating at $100^{\circ} \mathrm{C}$., equaling in this respect the highest grade rag half stock, despite the fact that they are on the average about 4 per cent lower in initial alpha cellulose content. They are distinctly superior to used white rag half stocks, although the alpha cellulose contents of the two materials are about the same. It will be further observed that sample No. 5 (a half stock prepared from used colored rags), although it has an alpha cellulose content within the range of those of the ordinary sulphite 
wood pulps studied, is much less stable than they are. Again, soda pulps are seen to be exceedingly resistant to the artificial aging test, considering the large amount of caustic-soluble material they contain. Referring to Figure 6, in which the relationship between original alpha cellulose content and percentage loss resulting from 72-hour heat treatment at $100^{\circ} \mathrm{C}$. is expressed graphically, it appears that the position of the curves for different types of fibers is determined by the character of the caustic-soluble constituents of these fibers. Apparently, a soda pulp having an alpha cellulose content of about 82 per cent would equal in stability a purified wood fiber of 94 per cent or a rag fiber of 98 per cent. This could be explained by assuming that the caustic-soluble impurities in wood pulps are, weight for weight, more passive in their deteriorating effects upon cellulose than those found in rag half stocks.

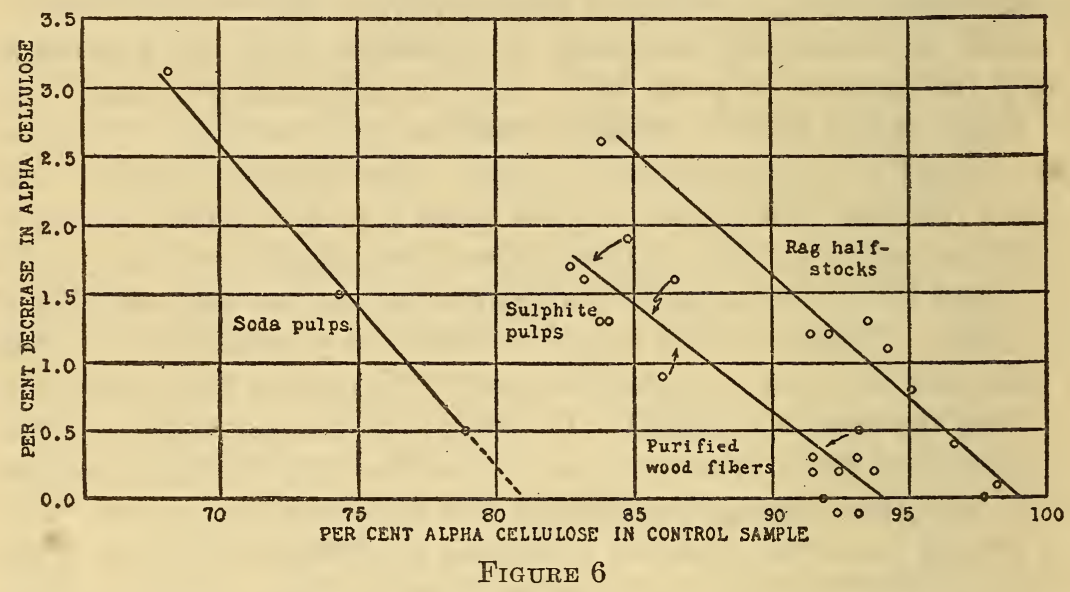

(2) Copper Number. - The copper numbers obtained for the various paper-making fibers are given in Table 2 , together with the values for heat-treated samples. The copper numbers of the new white rag half stocks range from 0.77 to 1.24 and appear to be slightly lower, on the average, than the copper numbers obtained on purified wood fibers, which range from 0.89 to 1.33. Other grades of rag half stock range in values from 0.93 to 2.55 . The ordinary types of wood fibers have considerably higher copper numbers than either the purified wood fibers or the better grades of half stock. In general, the lower the alpha cellulose content of fibers the higher will be its copper number. There are marked exceptions to this, however, the most striking being the soda pulps, which have a much lower alpha cellulose content than sulphite pulps; and yet they have in most cases lower copper numbers.

The increase in copper number after heating appears to offer no clue as to the probable relative permanence of the different types of 
fibers. In some cases the change apparently caused by the heating is within the range of experimental error, and therefore no great significance can be attached to the results.

(3) Pentosans. ${ }^{17}$-Only a limited number of pentosan values are given in Table 2 ; however, these values are probably representative of those which would be obtained on other materials of a given type of paper-making fiber. The rag half stocks here studied, contain extremely small, almost negligible, amounts of furfural-yielding substances, whereas all the wood fibers contain appreciable quantities. The purified wood fibers contain from 2 to more than 3 per cent, the ordinary sulphite wood pulp from over 3 to nearly 4 per cent, while the one sample of soda pulp tested had pentosans to the amount of 12 per cent. The fact that soda pulps do contain such large amounts of pentosans, and still have relatively good permanence qualities as compared to ordinary grades of sulphite pulps or poorer grades of rag half stock, suggests that these substances do not contribute to the deterioration of cellulose to nearly the extent that the modified celluloses do. The pentosan content of the purified wood fibers may also account for the fact that these fibers, approximately 4 per cent lower in alpha cellulose content than high-grade rag half stocks, are so comparatively stable toward the accelerated aging test; that is, a great part of the difference in the alpha cellulose contents of the two materials represents this content of relatively inert pentosans.

It was previously noted that soda pulps had lower copper numbers than the sulphite pulps, which are characterized by a higher alpha cellulose content. This is undoubtedly due to the fact that the pentosans, which are known to have no aldehyde groupings and consequently no reducing power toward Fehling's solution, are present in the former to a much greater extent.

(4) Other Tests.-The resin contents (alcohol-extractable materials) of the various fibers are given in Table 2. This impurity is present to a slight, and about the same, extent in new white rag half stock and in the purified wood fibers. In ordinary wood pulps and in the used grades of rag half stocks it is usually present in much greater amounts.

The ash contents of the various samples are also given in Table 2. With the exception of the soda pulps and a few of the poorest half stocks, these values are low and of little significance.

(b) PHYSICAL CHARACTERISTICS AND REACTION TOWARD ACCELERATED AGING TESTS

(1) Color Characteristics.-High whiteness and brilliance are usually desired qualities in fine papers, as is also the ability of the papers to preserve these qualities over long periods of time. The

17 Determinations made by K. S. Markley, associate chemist, Bureau of Standards.

$64338^{\circ}-29-10$ 
whiteness of fibers is often a direct indication of its chemical purity. The impurities generally indicated by poor color are the various natural coloring matters-resins, gums, lignin, etc. Cellulose fibers may, however, contain large quantities of oxycelluloses and yet have a highly brilliant color.

In order to obtain information on the color characteristics of the various paper-making fibers and likewise on the relative permanence of these qualities, sheets of the different samples were tested on the Pfund colorimeter and the color characteristics compared with those obtained on similar sheets heated for 72 hours at $100^{\circ} \mathrm{C}$. Colors were determined in terms of relative brightnesses for three different wave lengths of light (red, green, and blue). The values obtained are given in Table 4.

TABLE 4.-Color stability of various paper-making fibers

RAG HALF STOCKS

\begin{tabular}{|c|c|c|c|c|c|c|c|c|c|c|c|c|c|}
\hline \multirow{2}{*}{$\begin{array}{l}\text { Sample } \\
\text { No. }\end{array}$} & \multicolumn{4}{|c|}{$\begin{array}{l}\text { Brightness value of con- } \\
\text { trol sample }\end{array}$} & \multicolumn{4}{|c|}{$\begin{array}{l}\text { Brightness value of sam- } \\
\text { ple heated at } 100^{\circ} \mathrm{C} \text {. } \\
\text { for } 72 \text { hours }\end{array}$} & \multicolumn{4}{|c|}{$\begin{array}{l}\text { Decrease in brightness } \\
\text { values due to heating }\end{array}$} & \multirow{2}{*}{ Remarks } \\
\hline & Blue & Green & Red & $\begin{array}{l}\text { T'otal } \\
\text { bright- } \\
\text { ness } 1\end{array}$ & Blue & Green & Red & $\begin{array}{l}\text { Total } \\
\text { bright- } \\
\text { ness 1 }\end{array}$ & Blue & Green & Red & $\begin{array}{c}\text { Total } \\
\text { de- } \\
\text { crease }^{2}\end{array}$ & \\
\hline & $\begin{array}{r}0.84 \\
.84 \\
.84 \\
.83 \\
.83\end{array}$ & $\begin{array}{l}0.89 \\
.89 \\
.90 \\
.88 \\
.90\end{array}$ & $\begin{array}{r}0.92 \\
.92 \\
.93 \\
.92 \\
.92\end{array}$ & $\begin{array}{l}0.88 \\
.88 \\
.89 \\
.88 \\
.88\end{array}$ & $\begin{array}{r}0.82 \\
.82 \\
.82 \\
.80 \\
.78\end{array}$ & $\begin{array}{r}0.88 \\
.88 \\
.88 \\
.87 \\
.88\end{array}$ & $\begin{array}{r}0.92 \\
.92 \\
.93 \\
.91 \\
.92\end{array}$ & $\begin{array}{r}0.87 \\
.87 \\
.88 \\
.86 \\
.86\end{array}$ & $\begin{array}{r}0.02 \\
.02 \\
.02 \\
.03 \\
.05\end{array}$ & $\begin{array}{r}0.01 \\
.01 \\
.02 \\
.01 \\
.02\end{array}$ & $\begin{array}{r}0.00 \\
.00 \\
.00 \\
.01 \\
.00\end{array}$ & $\begin{array}{r}0.010 \\
.010 \\
.013 \\
.017 \\
.023\end{array}$ & $\begin{array}{l}\text { New white } \\
\text { rags. }\end{array}$ \\
\hline $\begin{array}{l}16 \ldots \ldots \\
8 \ldots \ldots \\
13 . \ldots . . . \\
10 \ldots \ldots \\
15 \\
5 \ldots\end{array}$ & $\begin{array}{l}.84 \\
.80 \\
.80 \\
.79 \\
.72\end{array}$ & $\begin{array}{l}.90 \\
.87 \\
.88 \\
.88 \\
.82\end{array}$ & $\begin{array}{l}.93 \\
.91 \\
.92 \\
.93 \\
.86 \\
.87\end{array}$ & $\begin{array}{l}.89 \\
.86 \\
.87 \\
.87 \\
.80\end{array}$ & $\begin{array}{l}.80 \\
.78 \\
.76 \\
.77 \\
.70\end{array}$ & $\begin{array}{l}.88 \\
.87 \\
.86 \\
.87 \\
.81 \\
.79\end{array}$ & $\begin{array}{l}.93 \\
.91 \\
.92 \\
.92 \\
.85\end{array}$ & $\begin{array}{l}.87 \\
.85 \\
.85 \\
.85 \\
.79 \\
.78\end{array}$ & $\begin{array}{l}.04 \\
.02 \\
.04 \\
.02 \\
.02\end{array}$ & $\begin{array}{l}.02 \\
.00 \\
.02 \\
.01 \\
.01 \\
.03\end{array}$ & $\begin{array}{l}.00 \\
.00 \\
.00 \\
.01 \\
.01 \\
.01\end{array}$ & $\begin{array}{l}.020 \\
.007 \\
.020 \\
.013 \\
.013 \\
.027\end{array}$ & $\begin{array}{l}\text { Old white } \\
\text { rags. } \\
\text { New colored } \\
\text { rags. } \\
\text { "Two's, and } \\
\text { blues." }\end{array}$ \\
\hline
\end{tabular}

PURIFIED WOOD PULPS

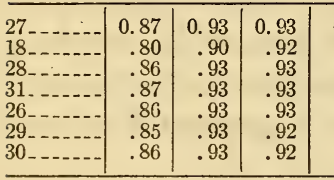

\begin{tabular}{l|l}
0.91 & 0.8 \\
.87 &. \\
.91 &. \\
.91 &. \\
.91 &. \\
.90 &. \\
.90 &.
\end{tabular}

\begin{tabular}{l|r|r|}
0.84 & 0.93 & 0.93 \\
.76 & .88 & .93 \\
.84 & .93 & .93 \\
.83 & .91 & .03 \\
.84 & .93 & .93 \\
.82 & .90 & .93 \\
.82 & .91 & .93
\end{tabular}

\begin{tabular}{r|r|}
0.90 & 0.03 \\
.86 & .04 \\
.90 & .02 \\
.89 & .04 \\
.90 & .02 \\
.88 & .03 \\
.89 & .04
\end{tabular}

\begin{tabular}{r|r|r|}
0.00 & 0.00 & 0.010 \\
.02 & .00 & .020 \\
.00 & .00 & .007 \\
.02 & .00 & .020 \\
.00 & .00 & .007 \\
.03 & .00 & .020 \\
.02 & .00 & .020
\end{tabular}

SULPHITE PULPS

\begin{tabular}{r|r|r|r|r|r|r|r|r|r|r|r|r|r}
\hline $20 \ldots \ldots \ldots$ & 0.78 & 0.90 & 0.93 & 0.87 & 0.71 & 0.86 & 0.92 & 0.83 & 0.07 & 0.04 & 0.01 & 0.040 & \\
19 \\
$23 \ldots$
\end{tabular}

SODA PULPS

\begin{tabular}{|c|c|c|c|c|c|c|c|c|c|c|c|c|}
\hline $\begin{array}{l}21 \\
4 \\
22\end{array}$ & $\begin{array}{r}0.66 \\
.70 \\
.67\end{array}$ & $\begin{array}{r}0.81 \\
.81 \\
.80\end{array}$ & $\begin{array}{r}0.89 \\
.89 \\
.89\end{array}$ & $\begin{array}{r}0.79 \\
.80 \\
.79\end{array}$ & $\begin{array}{r}0.62 \\
.65 \\
.64\end{array}$ & $\begin{array}{r}0.77 \\
.78 \\
.78\end{array}$ & $\begin{array}{r}0.88 \\
.88 \\
.88\end{array}$ & $\begin{array}{r}0.76 \\
.77 \\
.77\end{array}$ & $\begin{array}{r}0.04 \\
.05 \\
.03\end{array}$ & $\begin{array}{r}0.04 \\
.03 \\
.02\end{array}$ & $\begin{array}{r}0.01 \\
.01 \\
.01\end{array}$ & $\begin{array}{r}0.030 \\
.030 \\
.020\end{array}$ \\
\hline
\end{tabular}

1 Approximate brightness for white light. $\quad{ }^{2}$ Decrease in approximate brightness for white light. 
The higher and the more uniform the reflection coefficients for a given material are the closer does it approach a true white color. Pfund ${ }^{18}$ states: "**** if it reflects nonselectively it is to be called 'white.' According to this nomenclature, true grays are whites of different brightness." It will be seen that all the samples are inclined toward the yellow; that is, they are deficient in the blue reading. The new white rag half stocks and purified wood fibers, with the exception of No. 18, are examples of relatively good whites; on the other hand, the soda pulps are poor in color, since the values for the reflection coefficients diverge considerably and they are relatively low on the brightness scale. An approximate indication of the total brightness of the samples-that is, brightness for white light-is obtained by arbitrarily averaging the reflection coefficients for red, green, and blue. ${ }^{19}$ The color characteristics of the various samples of a particular group of paper-making fibers seem to be fairly typical for that particular group. For convenience these results have been composited and are expressed graphically in Figure 7. The curves approaching closest to a horizontal position represent the samples which are best in respect to nonselective reflection and thus the best whites. Relative brightnesses are indicated by the positions of the curves on the vertical scale. Color reversion, or the decrease in brightness, caused by accelerated aging, is represented in very nearly the correct proportion on the diagram by the distance between the green values for the original and for the heated sample.

Wood fibers prepared by the ordinary pulping processes (that is, sulphite and soda pulps) are much more seriously affected by the heat treatment than either the rag half stocks or purified wood fibers. The used white rag half stocks of high grade, although of a somewhat poorer initial color than half stocks prepared from new rags, do not appear to revert in color to any greater extent than the latter do. Purified wood fibers as well as high-grade rag fibers apparently retain their excellent initial color characteristics after the heating: Soda pulps appear to be somewhat more stable than the ordinary sulphite pulps in this respect.

(2) Microexamination of Heat-Treated Fibers. ${ }^{20}$ - It was thought that the degradation of the color and other properties of cellulose fibers might be indicative of the physical breaking of the individual fibers, and that some evidence of the change in physical structure might be obtained by examining the fibers microscopically before and after the 72-hour period of high-temperature treatment.

18 Pfund, A. H., A New Colorimeter for White Pigments and Some Results Obtained by Its Use, Am. Soc. Test. Materials, June, 1920.

10 In order to determine the true brightness for white light, readings would either have to be taken without the colored glasses or proper factors would have to be applied to the red, green, and blue readings before they were averaged. The excitation value for blue is small as compared to green and red.

${ }^{20}$ Examinations made by R. E. Lofton, associate physicist, Bureau of Standards. 
Accordingly, slides of typical fibers, both original and heated, were made up and examined at magnifications of 100,200,400, and 800 diameters. No difference, however, appeared between the untreated and the heat-treated fibers in any case. The fibers remained as

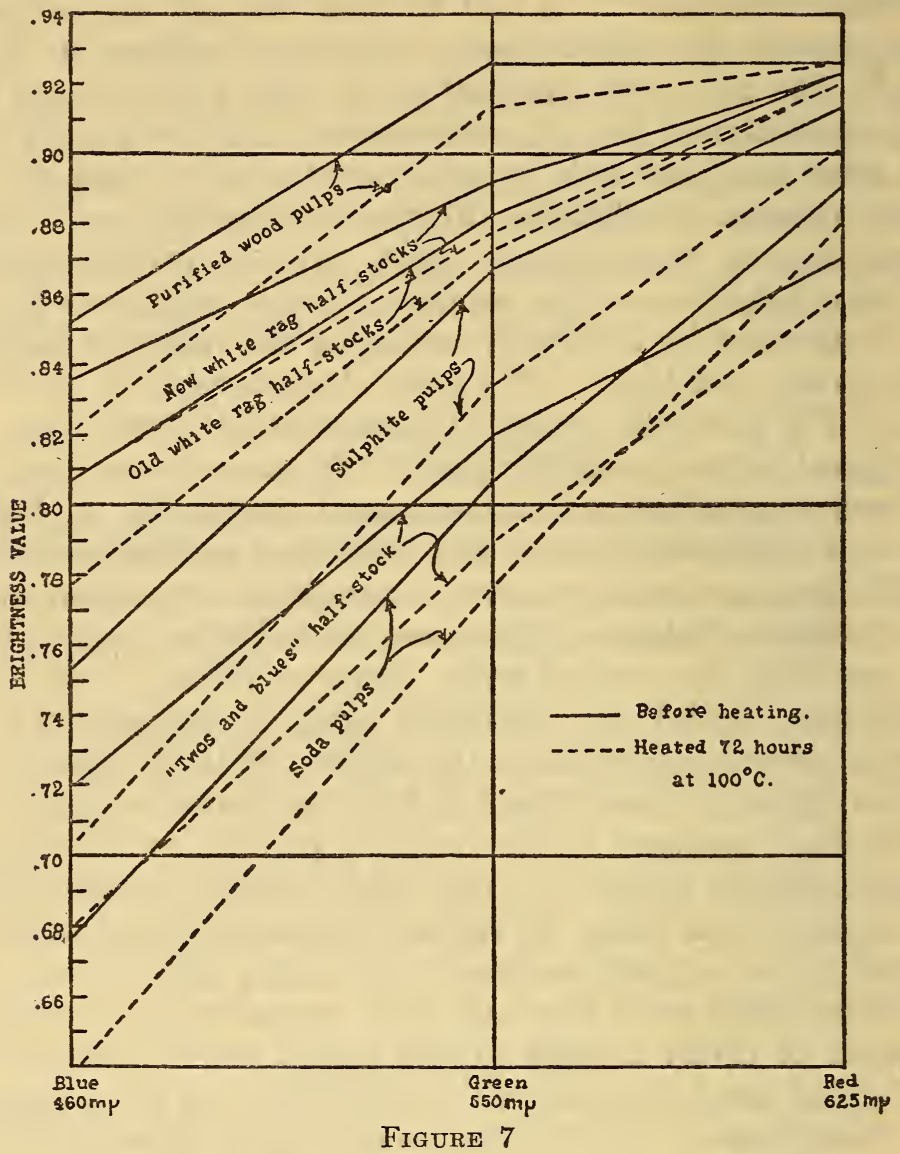

unbroken after treatment as they were originally, and no structure changes could be observed.

\section{PAPERS}

(a) DURABIITY AND PERMANENCE CHARACTERISTICS

(1) General Consideration of Strength Tests Applied to Papers.-All the commonly applied strength tests were made on original and artificially aged papers in order to compare their relative qualities of durability and permanence; that is, folding endurance, tearing strength, bursting strength, and tensile strength. The results obtained on each of the papers are given in Table 5. 


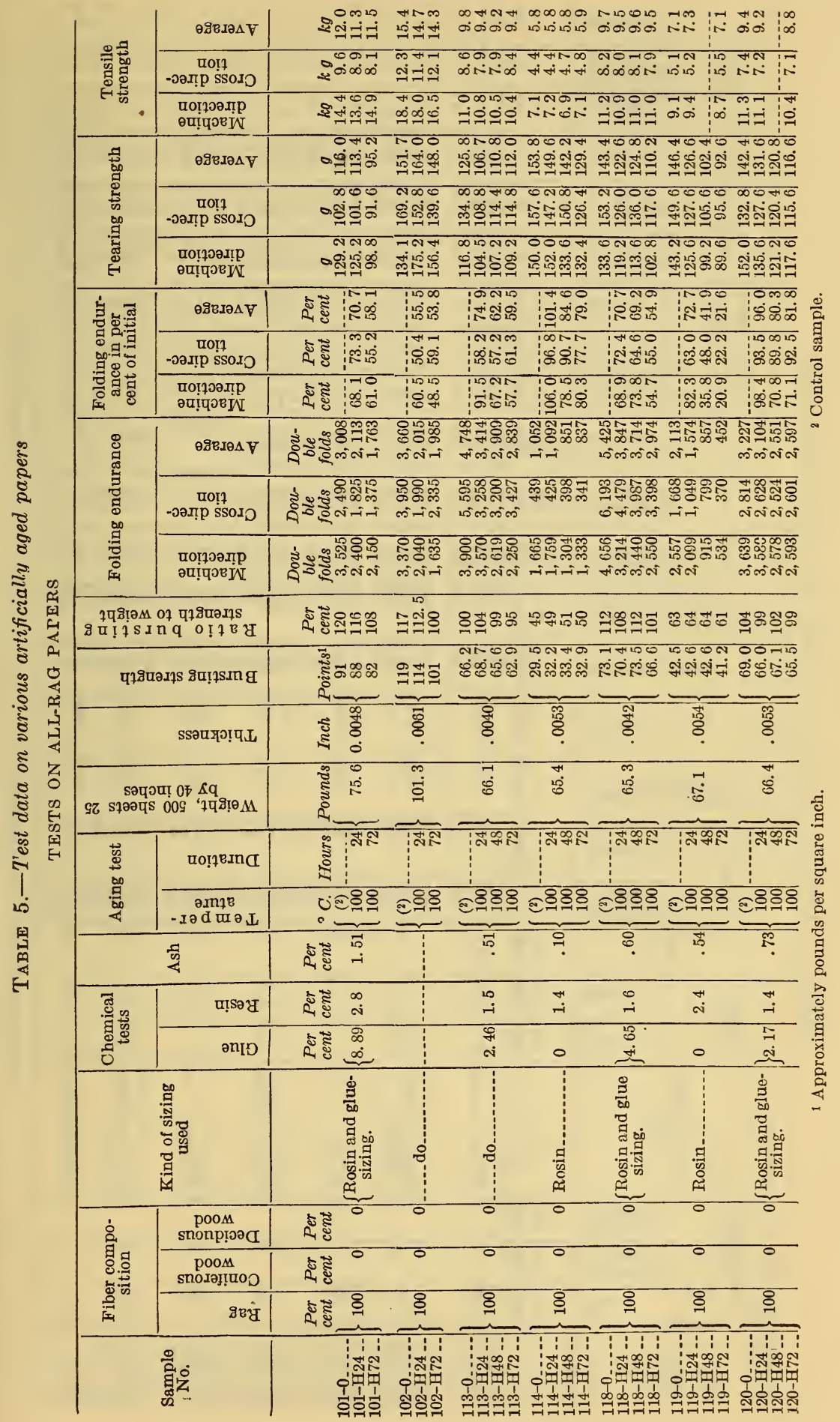




\begin{tabular}{|c|c|c|}
\hline \multirow{3}{*}{ 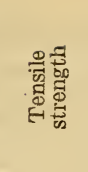 } & 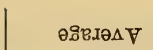 & 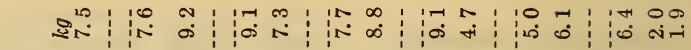 \\
\hline & 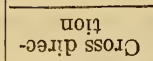 & 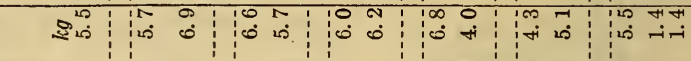 \\
\hline & 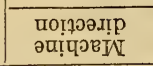 & 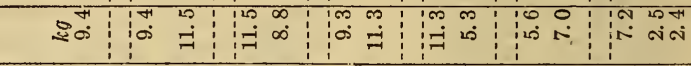 \\
\hline \multirow{3}{*}{ 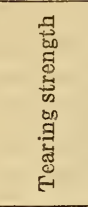 } & әอВอ..$\partial \Delta \mathrm{V}$ & 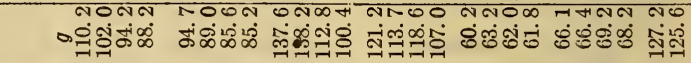 \\
\hline & 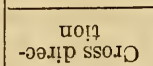 & 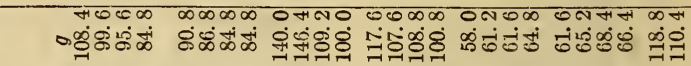 \\
\hline & 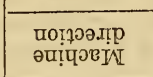 & 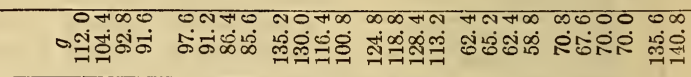 \\
\hline \multirow{3}{*}{ 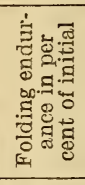 } & ๑.ి..$ə \Delta \mathrm{V}$ & 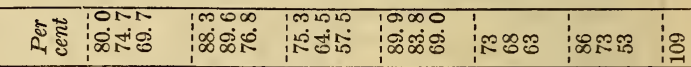 \\
\hline & 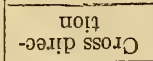 & 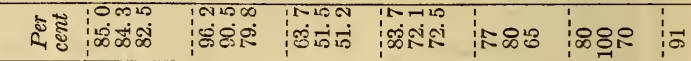 \\
\hline & 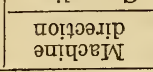 & 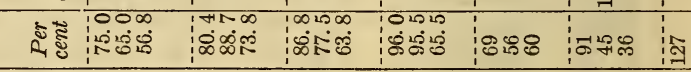 \\
\hline \multirow{3}{*}{ 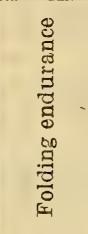 } & $8: \mathrm{B} \cdot . \partial \Delta \mathrm{V}$ & 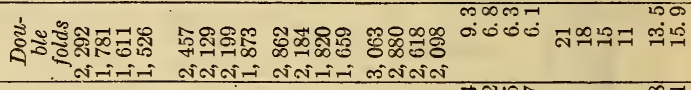 \\
\hline & 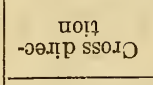 & 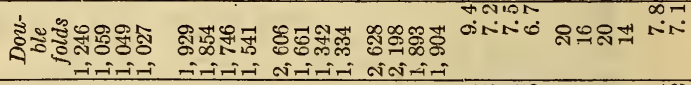 \\
\hline & 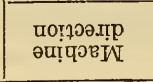 & 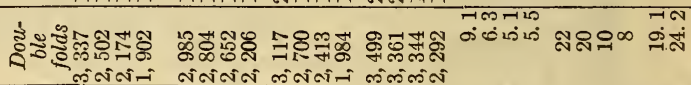 \\
\hline \multicolumn{2}{|c|}{ 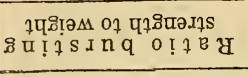 } & 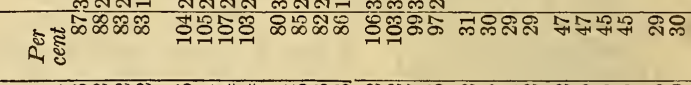 \\
\hline \multicolumn{2}{|c|}{ 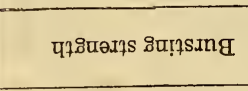 } & 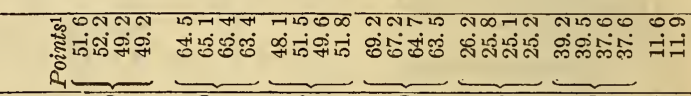 \\
\hline \multicolumn{2}{|r|}{ 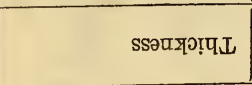 } & $\begin{array}{ll} \\
\text { है } \\
0 \\
0\end{array}$ \\
\hline \multicolumn{2}{|c|}{ 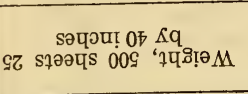 } & 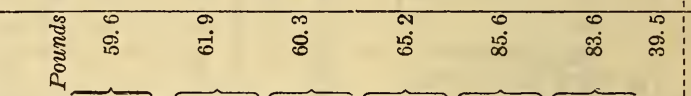 \\
\hline \multirow{2}{*}{ 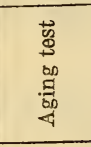 } & 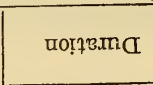 & 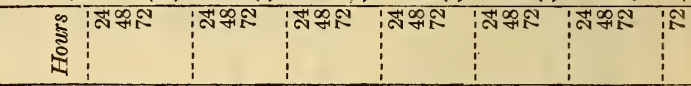 \\
\hline & 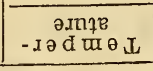 & ن \\
\hline \multicolumn{2}{|r|}{ 娄 } & 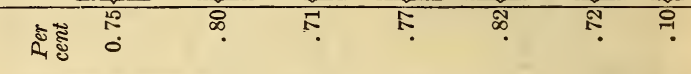 \\
\hline \multirow{2}{*}{ 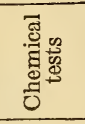 } & 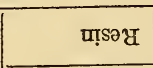 & 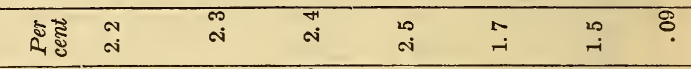 \\
\hline & əกเด & ڤँ है \\
\hline \multicolumn{2}{|r|}{ 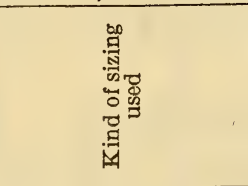 } & 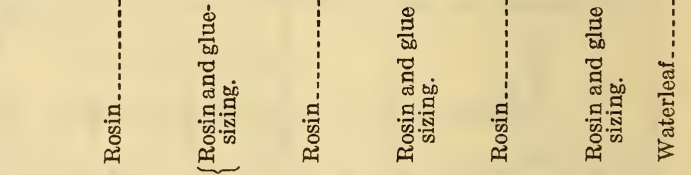 \\
\hline \multirow{3}{*}{ 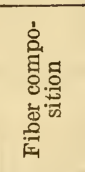 } & $\begin{array}{c}\text { poom } \\
\text { snonp!̣əə⿱亠䒑 }\end{array}$ & 过芯 \\
\hline & $\begin{array}{c}\text { poom } \\
\text { snoxoנ!uo }\end{array}$ & E है \\
\hline & ระช & 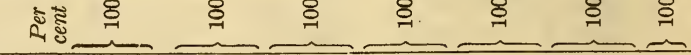 \\
\hline & 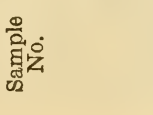 & 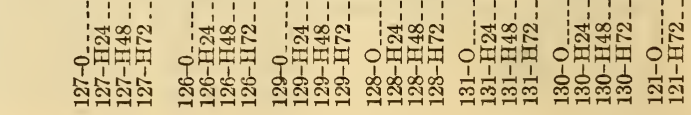 \\
\hline
\end{tabular}




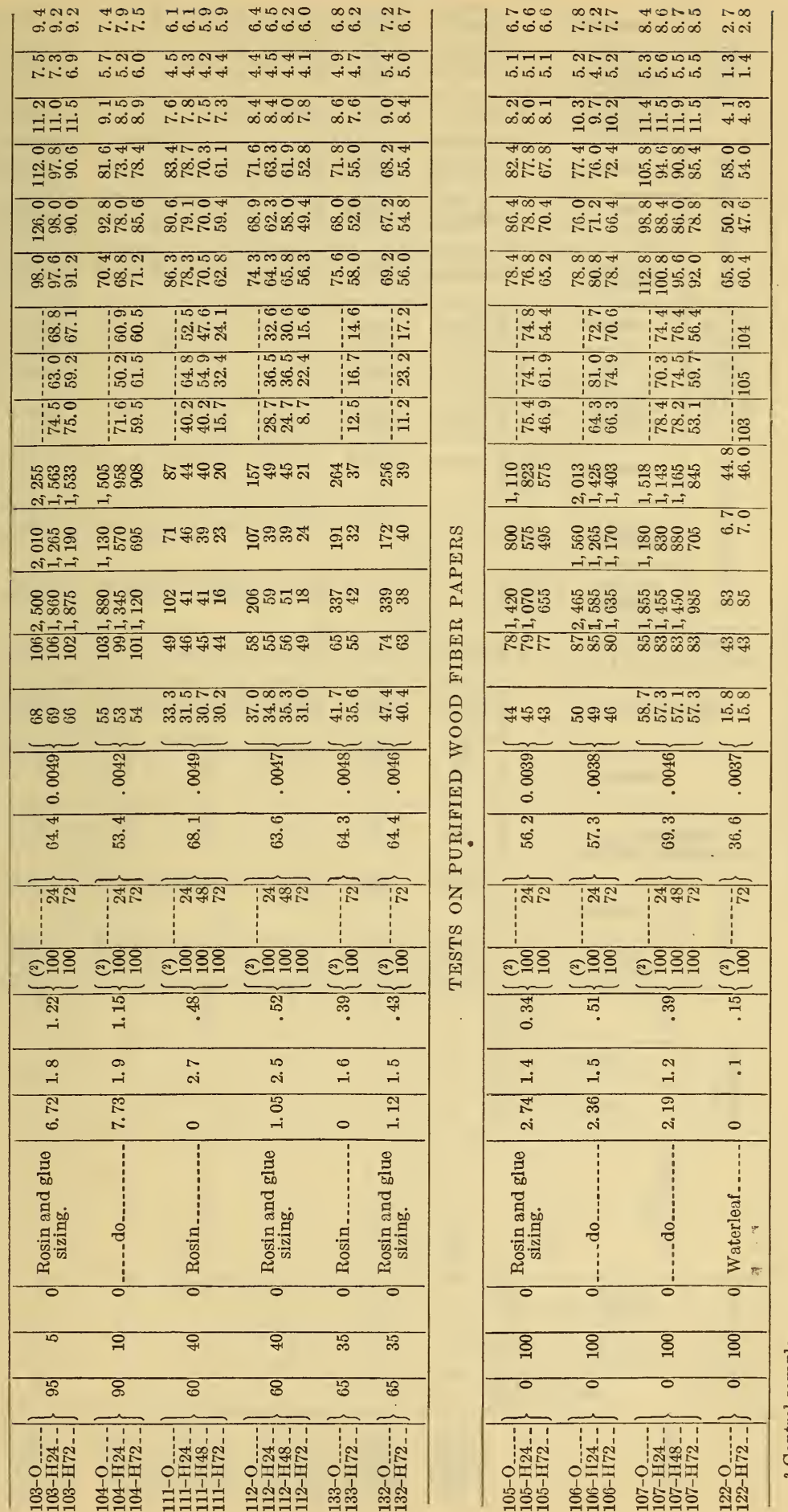




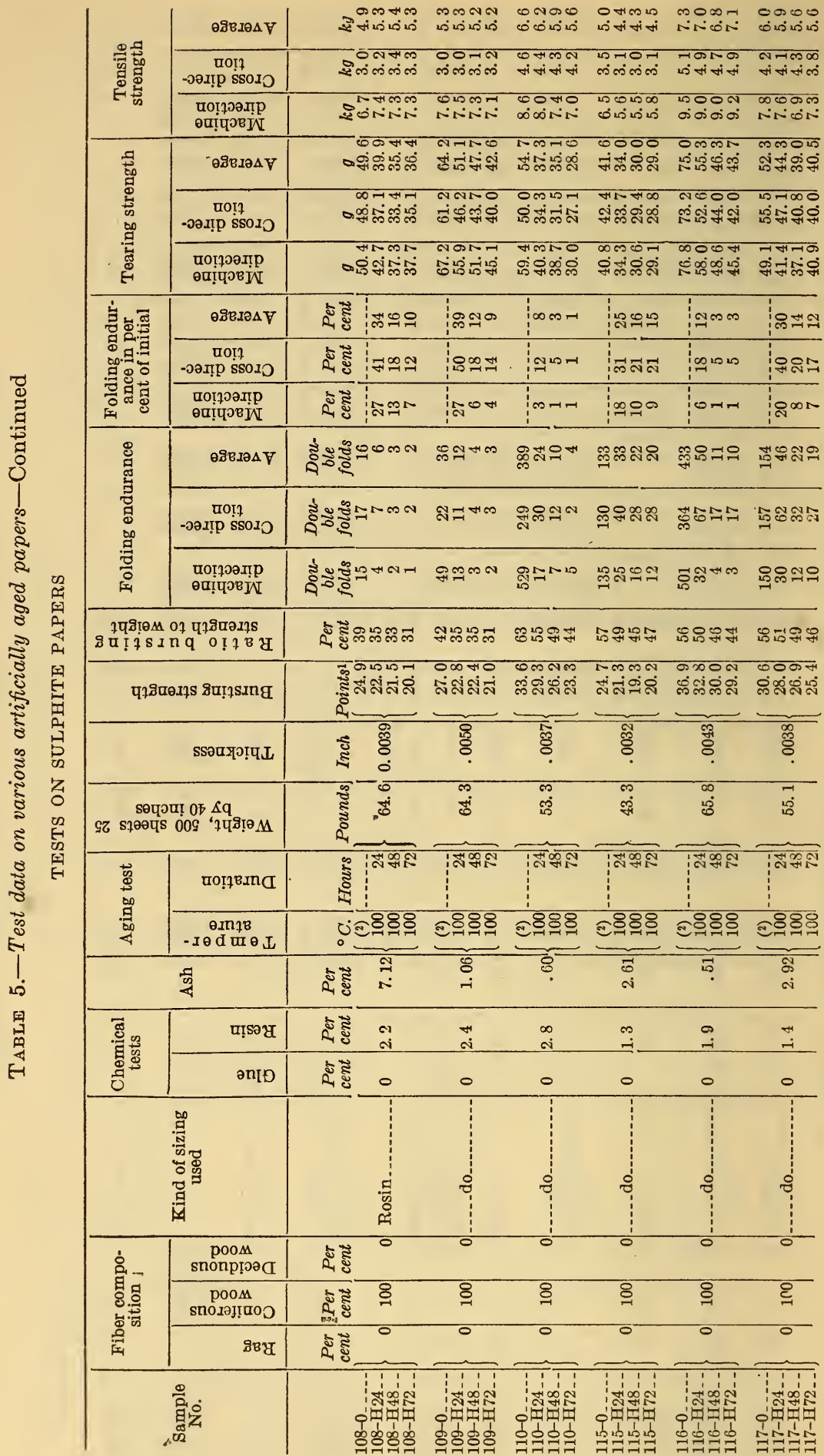




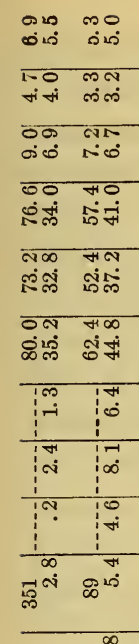

ลำ

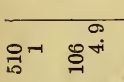

ㅁำ สำ

ना लन ถึ่ ลิ่

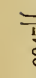

落产 :

$\overbrace{\text { กิ }}^{1 \mathrm{in}}$

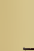

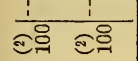

क्ष $-$

.

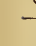

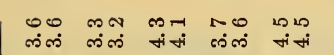

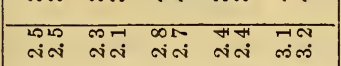

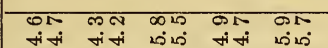

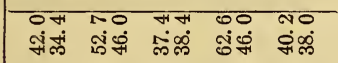

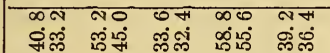

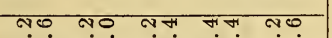

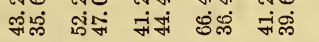

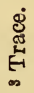

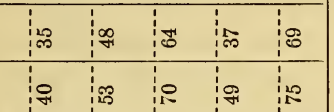

\&

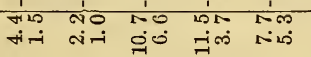

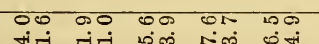

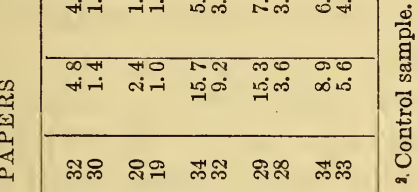

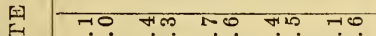

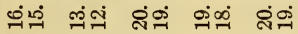

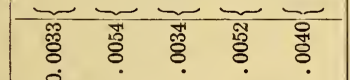

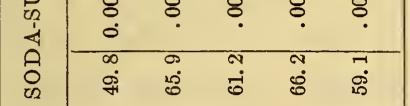

Z

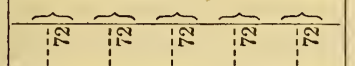

En

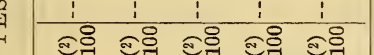

몀

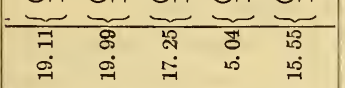

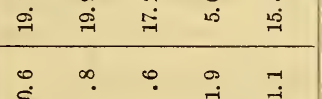

$\begin{array}{lllll}0 & 0 & 0 & -1 & -1\end{array}$

\begin{tabular}{lllll}
0 & 0 & 0 & 0 & 0 \\
\hline & 1 & 1 & 1 & 1
\end{tabular}

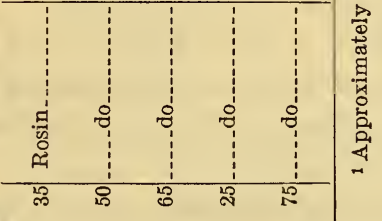

(1)

1.

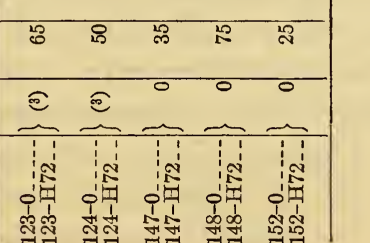


The folding endurance is generally considered to be the most valuable of the above tests in judging the probable durability or resistance of a paper to continued handling. Not only is the test indicative, in a general way, of the distinctive qualities of fibers in the papers, but the remarkable sensitivity of this test to heat or other arbitrary aging tests makes it a valuable means of classifying papers as to their probable permanence. Apart from the important effect of the quality of the basic fibers on the folding endurance of papers, the test is also influenced, in large part, by the treatment given the fiber. By referring to Table 5 it may be seen that the sulphite papers there represented vary from a few folds up to nearly 500 folds, although the variations in qualities of the pulps used for these papers were probably relatively slight. Among the rag papers even greater variations in folding endurance occur because of a greater variance among the factors affecting this test, which, aside from quality and purity of basic fiber, are treatment in the beater, method of sizing, quality of sizing materials, method of drying paper, etc.

The tearing test is probably more influenced by the strength of fibers in the paper than any of the other tests. On referring to the tests made on papers before and after being surface sized with glue, it will be observed that while the folding endurance, bursting, and tensile strength are all increased materially by the glue the tearing strength is not. The tearing test is of further interest in this work because of its sensitivity to the aging test. Artificially-aged papers decrease in tearing strength very sharply on being heated for 72 hours at $100^{\circ} \mathrm{C}$., although not to the same extent to which they do in folding endurance. It is interesting to note that a fair degree of correlation exists between the decrease in folding and the decrease in tearing strength resulting from the aging test.

Neither the bursting strength nor the tensile strength of papers is markedly affected by the heat treatment, except in cases where the papers are conspicuously of impermanent character or, in some cases, where the values may be said to be fictitious, in a sense, due to an abnormal amount of strength imparted by glue sizing.

(2) Discussion of Accelerated Aging Tests.-As a result of preliminary investigations of several types of accelerated aging tests, the usual one was found to be satisfactory and, in general, the most convenient. This test consists in placing the sample in an oven maintained at $100^{\circ} \mathrm{C}$. for a given length of time. In Table 5 strength values are given for papers which have been subjected to the heat test for 24, 48, and 72 hours. The effect of varying the duration of heat treatment on folding endurance is expressed graphically in Figures 8, 9, and 10 as per cent of initial folding endurance retained at the end of each period of exposure. A study of the curves indicates that a 72-hour period of heating is probably more desirable than a 
shorter period. At the end of 24 hours of heating the sharpest decrease in folding endurance takes place, especially among the less permanent types of papers, but reaches a more constant value between 48 and 72 hours. Therefore, the per cent of initial folding endurance
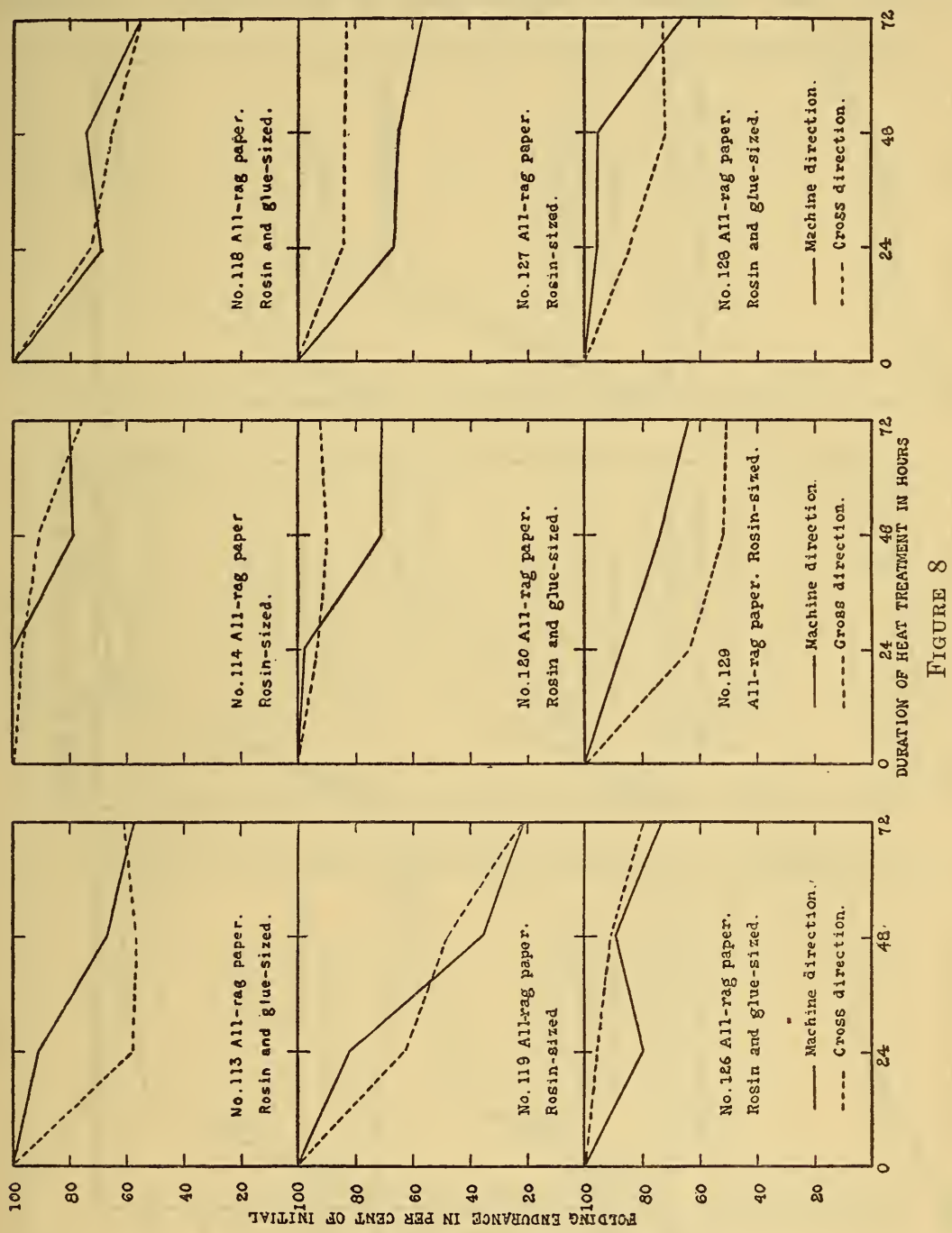

retained after a heat treatment of 72 hours at $100^{\circ} \mathrm{C}$. is considered the "permanency factor" of a given paper.

Another type of accelerated aging test, in which papers were exposed to a temperature of $95^{\circ} \mathrm{C}$. for 72 hours in an atmosphere of humidified air, was tried for different types of papers. Except for being somewhat less drastic than the latter, the relative effects were the same, and therefore the test was abandoned. 
A third type of aging test that was tried consisted in exposing the sample to the action of steam at atmospheric pressure for two hours. This treatment was found to be sufficient to cause a considerable reversion in the colors of the papers. It was found to be difficult to reproduce test results on papers aged in this manner, probably
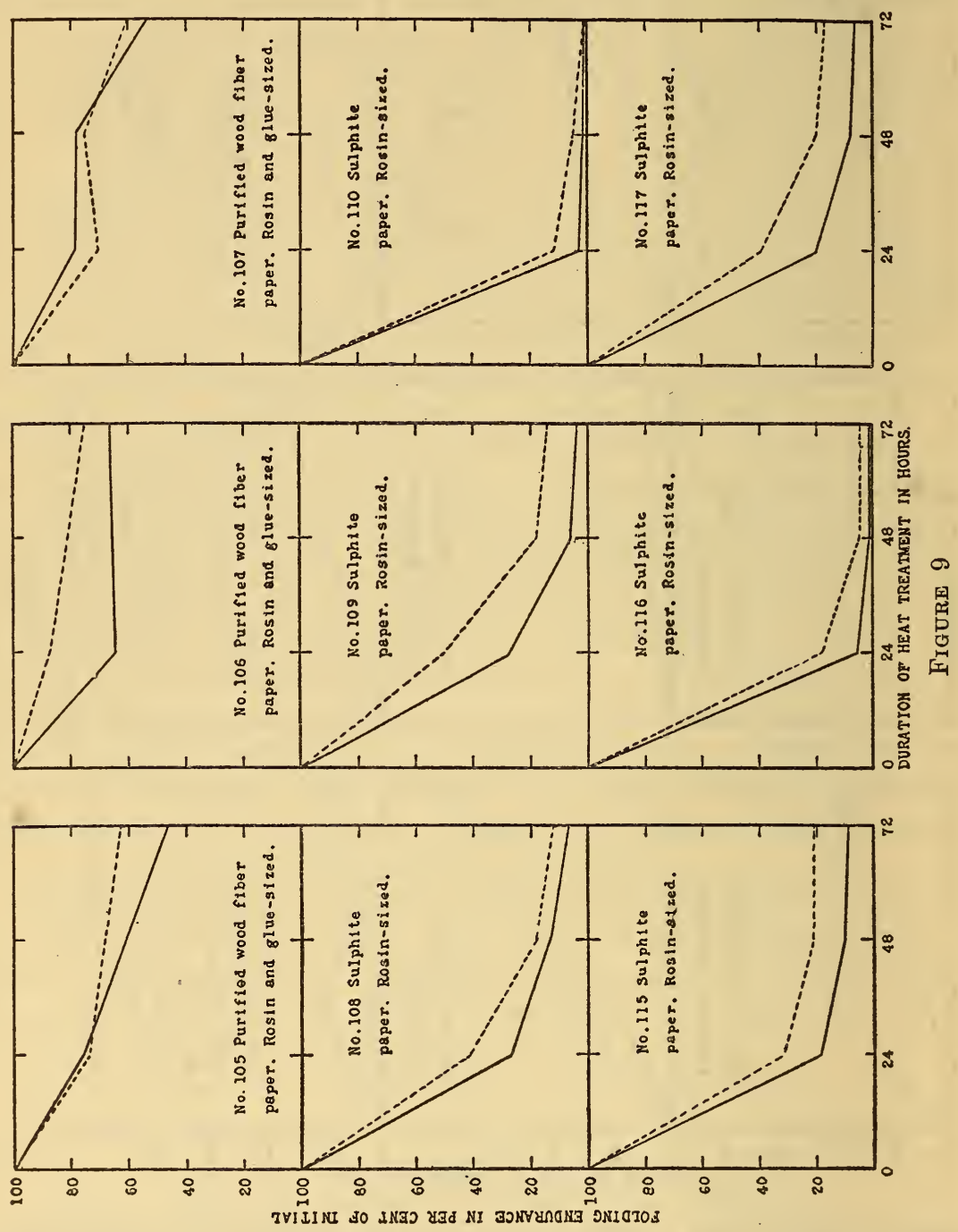

because of the fact that any condensate unavoidably dropping on the sheet, thus moistening it, would tend to give higher strength values. Glue-sized papers of all types decrease in folding endurance to about the same extent as a result of the steam exposure to which they do when heated in dry air at $100^{\circ} \mathrm{C}$. for 72 hours. Rosin-sized papers having no surface sizing of glue appear to be relatively much less 
affected. Similar steam treatments made on paper-making fibers of all types caused no decrease in the alpha cellulose of even the most impermanent of the fibers; therefore, it is probable that this type of artificial aging does not simulate the effects of natural aging nearly so closely as the ordinary heat test first considered.
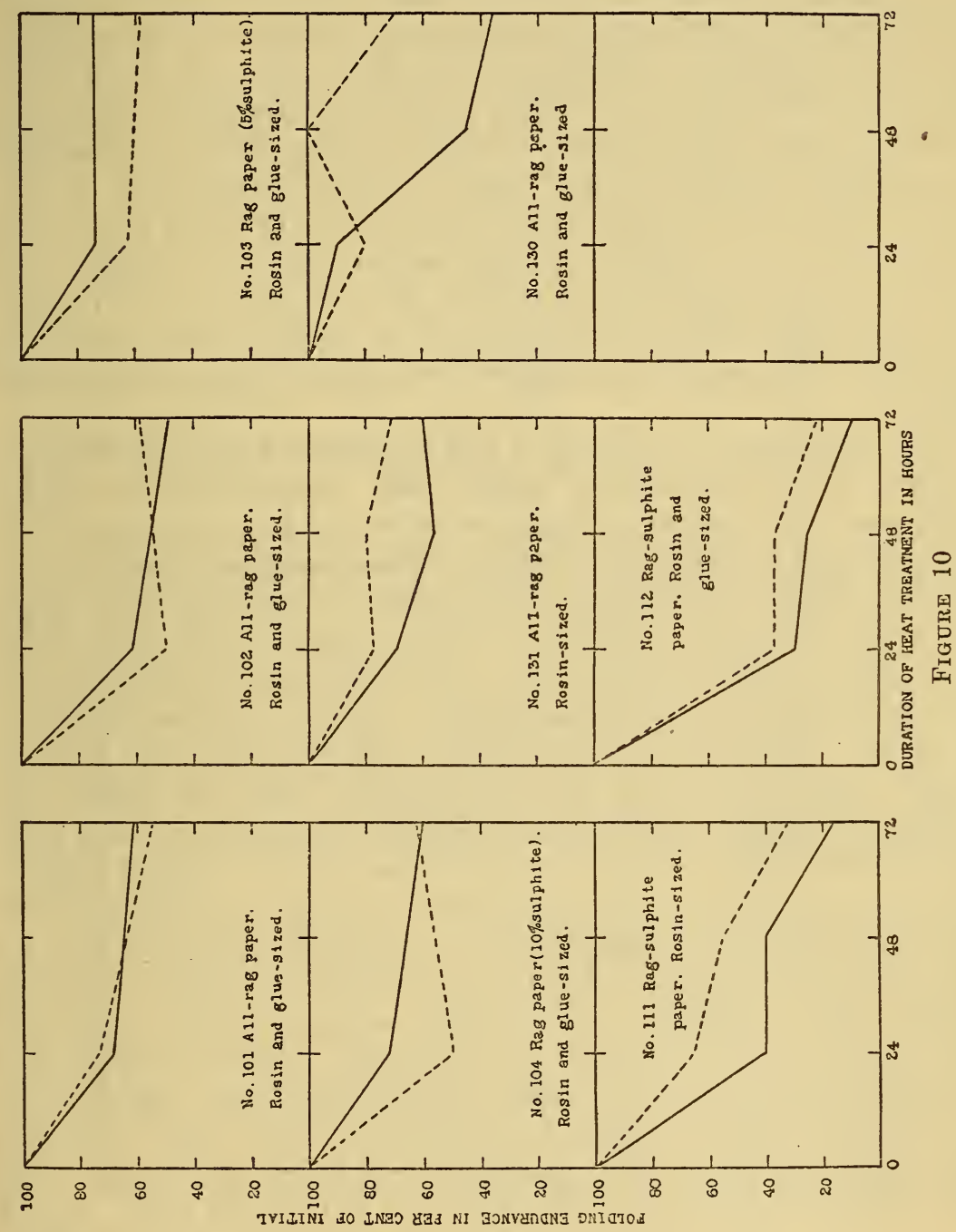

(3) Detailed Discussion of Results Obtained with Various PAPERs.-The book papers made from mixtures of soda pulps and sulphite pulps are considerably different from the other types of papers studied in that they have been made more with regard to printing qualities than for high strength or durability. They were included in this investigation for the purpose of learning more about 
the particular properties imparted to papers by the soda-pulp fiber. The test results given in Table 5 show that, while these papers are characterized by relatively very poor strength properties, they show a surprising resistance to the effects of artificial aging on these properties. In all cases the bursting, tearing, and tensile strengths are not altered to any marked degree by the heat treatment, and the retention of folding endurance is very high as compared with ordinary sulphite bond papers. The fact that papers of this type react to the aging test in the manner of fairly permanent papers may be due to several causes: First, the study of paper-making fibers indicated that soda pulps of sufficiently high alpha cellulose content may be considerably more permanent, chemically, than the ordinary wood fibers prepared by the sulphite process; second, the book papers here studied contain large amounts of filler, which is thought to favor permanency; third, they are practically all lightly sized, containing small amounts of rosin as compared to the other types of papers being studied.

Referring again to Table 5, it will be observed that the ordinary sulphite bond and writing papers vary considerably in folding endurance, from very low (samples 108-0 and 109-0) to fairly high (samples 110-0, 116-0, and 134-0). These variations may be due partly to differences existing in the quality of the basic fibers used, but are probably more largely due to the manner in which the fibers have been handled in the beater and on the paper machine. The strength properties of this class of papers are seen to be very sensitive to aging. The fact that the 72-hour heat treatment has left the papers extremely weak in folding endurance, while the tearing and bursting strengths have decreased decidedly, is considered fairly good evidence that they are quite definitely unsuited for purposes where a high degree of permanence is required. The variations among these papers in relative permanence are undoubtedly caused in part by differences existing in the chemical purity of the basic fibers and also unlike sizing conditions. The results, however, indicate that two other factors may be involved to some extent. It will be noted that the samples having relatively high initial strength characterisics, such as might be found in highly hydrated papers, are those which are the least permanent. Thus, samples 110-0, 116-0, and 134-0, which have folding endurances of 389,433 , and 351 , retain but 1,3 , and 1.3 per cent of this initial fold after 72 hours of heating at $100^{\circ} \mathrm{C}$. On the other hand, samples $108-0$ and 109-0, of markedly low original folding endurance, retain 10 and 9 per cent after the aging test. Although excessive hydration is considered a probable cause of deterioration, the presence of filler in the paper appears to have a beneficial effect. The papers containing filler, indicated by high ash 
content, all seem to be more resistant to the aging test than other papers containing no filler.

Three purified wood-fiber papers, surface sized with glue and otherwise prepared in a manner similar to high-grade rag papers, were available for this study. All these samples are characterized by very high strength qualities and in every respect appear to be entirely distinct in character from papers prepared from ordinary sulphite fibers. This superiority is particularly marked in regard to the folding endurance and the retention of this quality after the aging test. Sample 106-0 appears to combine best the qualities of durability and permanence, having an initial folding endurance of over 2,000 and losing but 29 per cent of this as a result of the 72-hour heat treatment. Sample 122 is a waterleaf paper made from purified wood fiber, and is used for the preparation of cellulose esters. It was included in this study in order to determine the permanence of this type of fiber when no sizing materials or other foreign substances affecting permanence had been added. The fact that the folding endurance suffers no appreciable change after the paper has been heated indicates a very high degree of permanence for this type of fiber.

The so-called part-rag papers consist of rag fiber and appreciable amounts of sulphite pulp. Samples $103-0$ and 104-0, while included under this classification in Table 5 because of the small amount of sulphite fiber which they contain, are not representative of this class of papers. The wood fiber probably entered as "broke" into the beater. The other papers containing 35 and 40 per cent sulphite pulp appear to be made with rag fibers that are relatively poor in strength and permanence qualities. None of these latter papers appears to be markedly superior to the better grades of ordinary sulphite bonds.

A considerable variety of all-rag papers were available for study and with few exceptions they have very good strength characteristics. Samples $130-0$ and $131-0$, which are particularly poor in folding endurance, were prepared from a "No. 1 white" grade of old rags. Sample 121-0 is a waterleaf paper, the fiber of which was undoubtedly not beaten to develop strength qualities, used for the preparation of cellulose esters. The fact that its initial folding endurance is not affected by the aging test indicates that the basic fiber is of very high permanence.

The number of rag papers sampled before and after the size tub affords an opportunity to study the effect of glue sizing on the various properties of papers. Referring to Table 5, it will be seen that the glue has increased the bursting and tensile strengths substantially, and the folding endurance to a widely varying extent and has decreased the tearing strength somewhat. 
It is indicated that when considerable strength has been imparted to paper by tub-sizing with glue, this added strength may be quite largely lost when the paper is heated. This decrease in strength may not be evidence of any great change in the strength of the basic fibers composing the sheet, nor does it necessarily indicate correspondingly poor permanence qualities for the paper. Samples 101-0, 102-0, and 118-0 all have high glue contents. It can not be stated just how much of the initial strength of samples 101-0 and 102-0 results from the use of glue sizing, since the corresponding unsized papers were not available. That considerable folding endurance has been imparted to sample 118-0 by the use of glue is known because its folding endurance is about fivefold that of the unsized paper corresponding to it, sample 114-0. It will be noted that the latter retained 79.0 per cent of its initial folding endurance on being heated 72 hours at $100^{\circ} \mathrm{C}$., while the glue-sized paper retained but 54.9 per cent. Also, samples 101-0 and 102-0 have decreased in folding endurance somewhat more rapidly than other papers of this type generally do. Even the bursting and tensile strengths undergo appreciable changes on heating, which is unusual for the more permanent papers.

In the case of other papers studied, however, where glue sizing has not increased the folding endurance to any great extent, the decrease in folding endurance caused by heating is usually somewhat greater for the unsized than for the sized paper. Samples 126-0 and 128-0 represent papers having folding endurance substantially the same as the unsized papers corresponding to them, 127-0 and 129-0. The per cent retention of folding endurance after heating 72 hours at $100^{\circ} \mathrm{C}$. is 76.8 and 69.0 for the glue-sized papers, as against 69.7 and 57.5 for the corresponding unsized papers. There is some indication here that the glue helps protect the fiber from deterioration. Later on evidence is offered to show that glue tub sizing does help to retard chemical degradation.

In Figure 11 is given a graphical representation of the comparative permanence of different types of papers, as determined by the per cent retention of folding endurance after the standard heat treatment of 72 hours at $100^{\circ} \mathrm{C}$. The purified wood fiber papers re-act to the aging test in much the same manner as the high-grade rag papers, and therefore it can reasonably be assumed that the resistance of these papers to the deterioration caused by natural aging would be of the same order. A comparison of the two types of papers from the standpoint of strength qualities or durability is made difficult because of the fact that only a limited number of purified wood fiber papers were available. While some of the rag papers test considerably higher in tearing strength and folding endurance, it can not be stated definitely, from the results tabulated, just how optimum papers prepared from the two fibers would compare. 
(b) COLOR CHARACTERISTICS

The color characteristics of the various papers reported in Table 6 are seen to have been markedly influenced by the color properties of the fibers from which these papers were made. In the study of wood pulps and rag half stocks, it was found that the sulphite pulps reverted the most in color as a result of the 72 -hour heat treatment at $100^{\circ} \mathrm{C}$. Similarly, the papers prepared from sulphite pulps are the most susceptible to reversion in color; both in respect to decrease in total brightness and in departure from true white, which latter character-

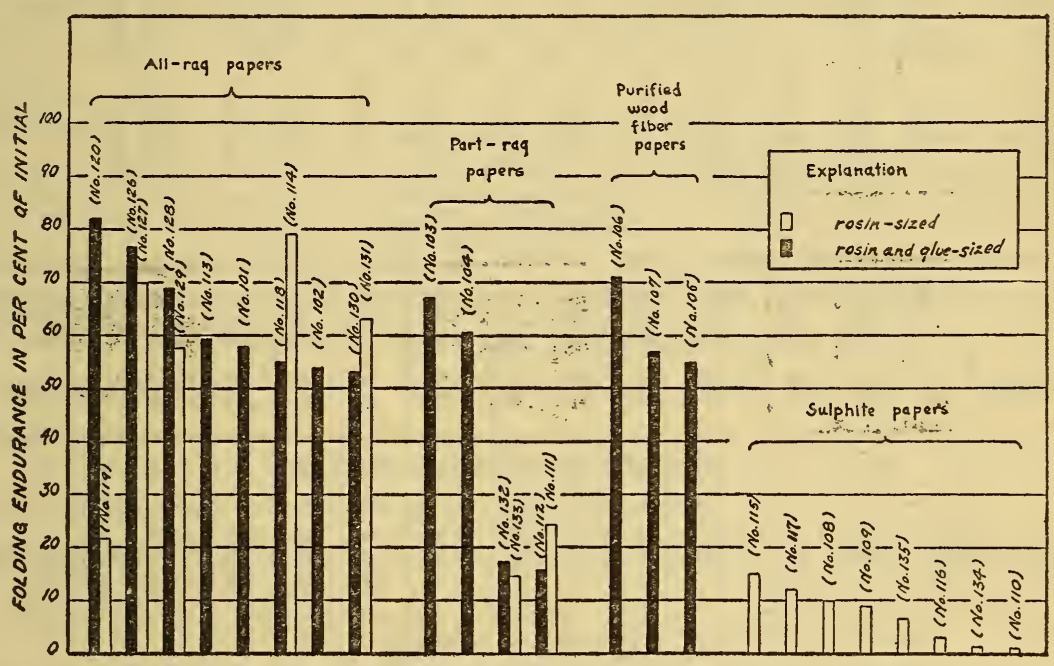

Figure 11

istic manifests itself as a relative increase in the predominating tintred. Next in order of susceptibility to reversion in color are the papers prepared from mixtures of sulphite pulps and rag fibers; then follow the book papers prepared from mixtures of sulphite pulps and soda pulps; and, finally, purified wood fiber papers and high-grade rag papers, which latter two appear to be about equal in color stability. In general, it is evident that papers which are impermanent in chemical or physical properties will also tend to discolor readily. Considering the sulphite papers alone, it is apparent that the three showing marked impermanence in regard to loss of physical strength after aging stand out as the papers reverting most in color. $64338^{\circ}-29-11$ 


\section{TABLE 6.-Color sibility of various commercial papers}

\section{ALL-RAG PAPERS}

\begin{tabular}{|c|c|c|c|c|c|c|c|c|c|c|c|c|c|}
\hline \multirow{2}{*}{$\begin{array}{l}\text { Sample } \\
\text { No. }\end{array}$} & \multicolumn{4}{|c|}{$\begin{array}{l}\text { Brightness value of con- } \\
\text { trol sample }\end{array}$} & \multicolumn{4}{|c|}{$\begin{array}{l}\text { Brightness value of sam- } \\
\text { ple heated at } 100^{\circ} \mathrm{C} \text {. } \\
\text { for } 72 \text { hours }\end{array}$} & \multicolumn{4}{|c|}{$\begin{array}{l}\text { Decrease in brightness } \\
\text { values due to heating }\end{array}$} & \multirow{2}{*}{ Remarks } \\
\hline & Blue & Green & Red & $\begin{array}{l}\text { Total } \\
\text { bright- } \\
\text { ness } 1\end{array}$ & Blue & Green & Red & $\begin{array}{l}\text { Total } \\
\text { bright- } \\
\text { ness } 1\end{array}$ & Blue & Green & Red & $\begin{array}{c}\text { Total } \\
\text { de- } \\
\text { crease } 2\end{array}$ & \\
\hline $\begin{array}{l}113 \\
118 \\
120 \\
126 \\
128 \\
130\end{array}$ & $\begin{array}{l}0.72 \\
.71 \\
.75 \\
.75 \\
.75 \\
.76\end{array}$ & $\begin{array}{l}0.84 \\
.78 \\
.81 \\
.84 \\
.85 \\
.83\end{array}$ & $\begin{array}{l}0.89 \\
.85 \\
.86 \\
.89 \\
.90 \\
.87\end{array}$ & $\begin{array}{l}0.82 \\
.78 \\
.81 \\
.83 \\
.83 \\
.82\end{array}$ & $\begin{array}{l}0.67 \\
.66 \\
.71 \\
.72 \\
.69 \\
.73\end{array}$ & $\begin{array}{l}0.81 \\
.74 \\
.78 \\
.83 \\
.83 \\
.81\end{array}$ & $\begin{array}{l}0.88 \\
.82 \\
.85 \\
.89 \\
.89 \\
.87\end{array}$ & $\begin{array}{l}0.79 \\
.74 \\
.78 \\
.81 \\
.80 \\
.80\end{array}$ & $\begin{array}{l}0.05 \\
.05 \\
.04 \\
.03 \\
.06 \\
.03\end{array}$ & $\begin{array}{l}0.03 \\
.04 \\
.03 \\
.01 \\
.02 \\
.02\end{array}$ & $\begin{array}{l}0.01 \\
.03 \\
.01 \\
.00 \\
.01 \\
.00\end{array}$ & $\begin{array}{r}0.030 \\
.040 \\
.027 \\
.013 \\
.030 \\
.017\end{array}$ & $\begin{array}{l}\text { Rosin and glue } \\
\text { sized. }\end{array}$ \\
\hline $\begin{array}{l}114 \\
119 \\
127 \\
129 \\
131\end{array}$ & $\begin{array}{l}.81 \\
.73 \\
.78 \\
.78 \\
.79\end{array}$ & $\begin{array}{l}.86 \\
.79 \\
.87 \\
.87 \\
.85\end{array}$ & $\begin{array}{l}.92 \\
.84 \\
.91 \\
.91 \\
.89\end{array}$ & $\begin{array}{l}.86 \\
.86 \\
.85 \\
.85 \\
.84\end{array}$ & $\begin{array}{l}.78 \\
.68 \\
.72 \\
.73 \\
.72\end{array}$ & $\begin{array}{l}.85 \\
.75 \\
.86 \\
.86 \\
.83\end{array}$ & $\begin{array}{l}.91 \\
.82 \\
.91 \\
.91 \\
.89\end{array}$ & $\begin{array}{l}.85 \\
.75 \\
.83 \\
.83 \\
.81\end{array}$ & $\begin{array}{l}.03 \\
.05 \\
.06 \\
.05 \\
.07\end{array}$ & $\begin{array}{l}.01 \\
.04 \\
.01 \\
.01 \\
.02\end{array}$ & $\begin{array}{l}.01 \\
.02 \\
.00 \\
.00 \\
.00\end{array}$ & $\begin{array}{l}.017 \\
.037 \\
.023 \\
.020 \\
.030\end{array}$ & Rosin sized. \\
\hline
\end{tabular}

PART-RAG PAPERS

\begin{tabular}{|c|c|c|c|c|c|c|c|c|c|c|c|c|c|}
\hline $\begin{array}{l}112 \ldots \\
132 \ldots \\
104 \ldots\end{array}$ & $\begin{array}{r}0.72 \\
.69 \\
.72\end{array}$ & $\begin{array}{r}0.74 \\
.74 \\
.78\end{array}$ & $\begin{array}{r}0.82 \\
.79 \\
.82\end{array}$ & $\begin{array}{r}0.76 \\
.74 \\
.77\end{array}$ & $\begin{array}{r}0.64 \\
.60 \\
.67\end{array}$ & $\begin{array}{r}0.72 \\
.71 \\
.76\end{array}$ & $\begin{array}{r}0.80 \\
.78 \\
.82\end{array}$ & $\begin{array}{r}0.72 \\
.70 \\
.75\end{array}$ & $\begin{array}{r}0.08 \\
.09 \\
.05\end{array}$ & $\begin{array}{r}0.02 \\
.03 \\
.02\end{array}$ & $\begin{array}{r}0.02 \\
.01 \\
.00\end{array}$ & $\begin{array}{r}0.040 \\
.043 \\
.023\end{array}$ & $\begin{array}{l}\text { Rosin and giue } \\
\text { sized. }\end{array}$ \\
\hline $111 \ldots$ & .71 & .75 & $\begin{array}{l}.80 \\
.81\end{array}$ & .75 & $\begin{array}{l}.61 \\
.64\end{array}$ & $\begin{array}{l}.73 \\
.73\end{array}$ & $\begin{array}{l}.80 \\
.80\end{array}$ & $\begin{array}{l}.73 \\
.72\end{array}$ & $\begin{array}{l}.10 \\
.09\end{array}$ & $\begin{array}{l}.02 \\
.04\end{array}$ & $\begin{array}{l}.00 \\
.01\end{array}$ & $\begin{array}{l}.040 \\
.047\end{array}$ & Rosin sized. \\
\hline
\end{tabular}

PURIFIED WOOD-FIBER PAPERS

\begin{tabular}{|c|c|c|c|c|c|c|c|c|c|c|c|c|c|}
\hline $\begin{array}{l}105 \\
106 \\
107\end{array}$ & $\begin{array}{r}0.75 \\
.71 \\
.73\end{array}$ & $\begin{array}{r}0.82 \\
.76 \\
.77\end{array}$ & $\begin{array}{r}0.86 \\
.81 \\
.82\end{array}$ & $\begin{array}{r}0.81 \\
.76 \\
.77\end{array}$ & $\begin{array}{r}0.70 \\
.68 \\
.70\end{array}$ & $\begin{array}{r}0.80 \\
.75 \\
.75\end{array}$ & $\begin{array}{r}0.86 \\
.81 \\
.81\end{array}$ & $\begin{array}{r}0.79 \\
.75 \\
.75\end{array}$ & $\begin{array}{r}0.05 \\
.03 \\
.03\end{array}$ & $\begin{array}{r}0.02 \\
.01 \\
.02\end{array}$ & $\begin{array}{r}0.00 \\
.00 \\
.01\end{array}$ & $\begin{array}{r}0.023 \\
.013 \\
.020\end{array}$ & $\left\{\begin{array}{l}\text { Rosin and glue } \\
\text { sized. }\end{array}\right.$ \\
\hline
\end{tabular}

\section{SULPHITE PAPERS}

\begin{tabular}{|c|c|c|c|c|c|c|c|c|c|c|c|c|c|}
\hline $\begin{array}{l}108 \\
109 \\
110 \\
115 \\
116 \\
117 \\
135\end{array}$ & $\begin{array}{r}0.75 \\
.73 \\
.73 \\
.70 \\
.71 \\
.72 \\
.75\end{array}$ & $\begin{array}{r}0.80 \\
.79 \\
.77 \\
.77 \\
.76 \\
.78 \\
.86\end{array}$ & $\begin{array}{r}0.84 \\
.84 \\
.82 \\
.83 \\
.81 \\
.83 \\
.90\end{array}$ & $\begin{array}{r}0.80 \\
.79 \\
.77 \\
.77 \\
.76 \\
.78 \\
.84\end{array}$ & $\begin{array}{r}0.66 \\
.64 \\
.61 \\
.65 \\
.60 \\
.63 \\
.68\end{array}$ & $\begin{array}{r}0.76 \\
.75 \\
.71 \\
.74 \\
.72 \\
.77 \\
.79\end{array}$ & $\begin{array}{r}0.83 \\
.83 \\
.80 \\
.82 \\
.80 \\
.83 \\
.88\end{array}$ & $\begin{array}{r}0.75 \\
.74 \\
.71 \\
.74 \\
.71 \\
.74 \\
.77\end{array}$ & $\begin{array}{r}0.09 \\
.09 \\
.12 \\
.05 \\
.11 \\
.09 \\
.10\end{array}$ & $\begin{array}{r}0.04 \\
.04 \\
.06 \\
.03 \\
.04 \\
.01 \\
.07\end{array}$ & $\begin{array}{r}0.01 \\
.01 \\
.02 \\
.01 \\
.01 \\
.00 \\
.02\end{array}$ & $\begin{array}{r}0.047 \\
.047 \\
.067 \\
.030 \\
.053 \\
.033 \\
.063\end{array}$ & Rosin sized. \\
\hline
\end{tabular}

SODA-SULPHITE PAPERS

\begin{tabular}{|c|c|c|c|c|c|c|c|c|c|c|c|c|c|}
\hline $\begin{array}{l}123 \ldots \ldots \\
124 \\
147 \\
148 \ldots \ldots \\
152 \ldots \ldots\end{array}$ & $\begin{array}{r}0.74 \\
.75 \\
.68 \\
.69 \\
.65\end{array}$ & $\begin{array}{r}0.82 \\
.84 \\
.74 \\
.77 \\
.79\end{array}$ & $\begin{array}{r}0.87 \\
.89 \\
.83 \\
.86 \\
.87\end{array}$ & $\begin{array}{r}0.81 \\
.83 \\
.75 \\
.77 \\
.77\end{array}$ & $\begin{array}{r}0.69 \\
.72 \\
.61 \\
.61 \\
.61\end{array}$ & $\begin{array}{r}0.80 \\
.83 \\
.72 \\
.74 \\
.77\end{array}$ & $\begin{array}{r}0.87 \\
.89 \\
.82 \\
.85 \\
.87\end{array}$ & $\begin{array}{r}0.79 \\
.81 \\
.72 \\
.73 \\
.75\end{array}$ & $\begin{array}{r}0.05 \\
.03 \\
.07 \\
.08 \\
.04\end{array}$ & $\begin{array}{l}0.02 \\
.01 \\
.02 \\
.03 \\
.02\end{array}$ & $\begin{array}{r}0.00 \\
.00 \\
.01 \\
.01 \\
.00\end{array}$ & $\begin{array}{r}0.023 \\
.013 \\
.033 \\
.040 \\
.020\end{array}$ & Rosin sized. \\
\hline
\end{tabular}

1 Approximate brightness for white light.

2 Decrease in approximate brightness for white light.

Another effect apparent in the color characteristics of the papers may be mentioned. Referring to the results obtained for rag papers, it will be observed that the glue-sized papers tend to be more sensitive to color changes than similar papers sampled before tub sizing. 
(c) ERASING QUALITY OF BOND PAPERS MADE FROM RAG FIBERS AND FROM PURIFIED WOOD FIBERS

Tests were made of the erasing quality of rag papers as compared with that of certain purified wood-fiber papers. In order to obtain some preliminary information on this subject, two papers prepared from the highest grade of rag half stock were subjected to erasure tests and compared, in this respect, with three available papers prepared from purified wood fibers. All papers were rosin and glue sized and contained approximately the same amounts of these sizing materials. A description of the test procedure used follows.

Straight lines were drawn with a ruling pen with standard testing ink, making a more or less average width line as in normal pen writing.

The quality of each consecutive line drawn after the erasure of the middle portion of the original line was noted; and the sum total of the repeated erasure of lines drawn in the same place until the rubbing through of the sheet occurred was used as a basis for comparison of samples. The reason for erasing only the middle portion of each line is to leave the ends as a guide for the new line after each erasure. The above test was checked for each sample to insure accuracy.

The surface of the paper after erasure also was noted and had some bearing on the decision of relative merits.

The faults noted were feathering of the pen lines and a skipping of the ink on the lines.

All of the papers were found to have good erasing quality. The test data are given in Table 7 in order of the relative ranking of the papers in respect to resistance to erasing, No. 113 being considered the best and No. 120 the poorest.

$\mathrm{T}_{\mathrm{ABLE}}$ 7.-Erasure tests 1

\begin{tabular}{|c|c|c|c|c|}
\hline $\begin{array}{l}\text { Sample } \\
\text { No. }\end{array}$ & Description & $\begin{array}{c}\text { Weight, } \\
500 \text { sheets } \\
25 \text { by } 40 \\
\text { inches }\end{array}$ & Rosin & Glue \\
\hline $\begin{array}{ll}113-\ldots . \\
107-. .\end{array}$ & $\begin{array}{l}100 \text { per cent rag bond. Rosin and glue sized. } \\
100 \text { per cent purified wood fiber bond paper. Rosin and glue }\end{array}$ & $\begin{array}{r}\text { Pounds } \\
66.1\end{array}$ & $\begin{array}{r}\text { Per cent } \\
1.53\end{array}$ & $\begin{array}{r}\text { Per cent } \\
2.46\end{array}$ \\
\hline $\begin{array}{l}106 . . \\
105 \ldots\end{array}$ & & $\begin{array}{l}69.3 \\
57.3 \\
56.2\end{array}$ & $\begin{array}{l}1.24 \\
1.53 \\
1.41\end{array}$ & $\begin{array}{l}2.19 \\
2.36 \\
2.74\end{array}$ \\
\hline 120 & 100 per cent rag bond. Rosin and glue sized. & 66.4 & 1.35 & 2.17 \\
\hline
\end{tabular}

1 Papers are arranged in order of their erasure qualities, No. 113 being considered the best.

The data indicate that high-grade rag papers and papers prepared from purified wood fibers withstand erasure to about the same extent. The probabilities are that fiber composition has only a minor influence on this particular quality of paper and that other factors entering 
into its manufacture (for example, quality and amount of sizing materials and treatment of fibers in the beater) have a much more important effect.

\section{(d) ALPHA CELLULOSE CONTENT}

The effect of the artificial aging test on the alpha cellulose content of some typical papers is given in Table 8. Referring to Table 5, it is evident that there is a correlation between the decrease in folding endurance and the decrease in alpha cellulose content. For example, the sulphite papers and those prepared from mixtures of sulphite pulp and rags, which dropped markedly in folding endurance when heated for 72 hours at $100^{\circ} \mathrm{C}$, revealed a corresponding instability in alpha cellulose content; on the other hand, the purified woodfiber papers and all-rag papers of relatively good permanence lost less than 2 per cent. To illustrate the effect on an all-rag paper of poor permanence, sample 119-0, which retained but 21.6 per cent of its initial folding endurance after the heat treatment, dropped 6.0 per cent in alpha cellulose. It may be noted that the surface-sized papers are more stable in this respect than similar papers sampled before tub sizing;, suggesting, as was indicated before, that the surface coating of glue may actually assist the aging qualities of a paper.

TABLE 8.-Decrease in alpha cellulose content of papers on heating for 72 hours at $100^{\circ} \mathrm{C}$.

ALI-RAG PAPERS

\begin{tabular}{|c|c|c|c|c|}
\hline \multirow[b]{2}{*}{ Y } & \multirow[b]{2}{*}{ Sample No. } & \multicolumn{3}{|c|}{ Alpha cellulose content } \\
\hline & & $\begin{array}{l}\text { Control } \\
\text { sample }\end{array}$ & $\begin{array}{c}\text { Sample } \\
\text { heated } \\
72 \text { hours } \\
\text { at } 100^{\circ} \\
\text { C. }\end{array}$ & $\begin{array}{l}\text { Amount } \\
\text { of initial } \\
\text { alpha } \\
\text { cellulose } \\
\text { lost }\end{array}$ \\
\hline $\begin{array}{l}119 \ldots \\
120 \ldots \\
114 \\
118 . .\end{array}$ & & $\begin{array}{r}\text { Per cent } \\
90.7 \\
91.0 \\
97.5 \\
89.1\end{array}$ & $\begin{array}{r}\text { Per cent } \\
85.2 \\
89.7 \\
96.5 \\
88.6\end{array}$ & $\begin{array}{r}\text { Per cent } \\
6.0 \\
1.4 \\
1.0 \\
.6\end{array}$ \\
\hline
\end{tabular}

PART-RAG PAPERS

\begin{tabular}{|c|c|c|c|}
\hline $111 \ldots \ldots$ & 79.8 & 73.6 & 7.8 \\
\hline 112 & 78. 9 & 73.9 & 6.3 \\
\hline 133 & 77.7 & 73.3 & 5. 7 \\
\hline 132 & 78.1 & 74.4 & 4. 7 \\
\hline
\end{tabular}

PURIFIED WOOD-FIBER PAPERS

\begin{tabular}{|c|c|c|c|}
\hline 106 & $\begin{array}{l}86.8 \\
85.3 \\
85.3\end{array}$ & $\begin{array}{l}85.8 \\
83.7 \\
83.7\end{array}$ & $\begin{array}{l}1.1 \\
1.9 \\
1.9\end{array}$ \\
\hline
\end{tabular}

\begin{tabular}{|c|c|c|c|}
\hline 108 & $\begin{array}{l}76.1 \\
79.3\end{array}$ & $\begin{array}{l}71.8 \\
74.6\end{array}$ & $\begin{array}{l}5.7 \\
5.9\end{array}$ \\
\hline
\end{tabular}




\section{FURTHER WORK}

1. A method is very much needed for identifying purified wood fibers in papers. A satisfactory estimation of the purified fibers in the presence of sulphite fibers can not be readily made by means of any of the stains commonly used in fiber-analysis work. An attempt is being made to devise some stain which will differentiate these fibers.

2. It has been noted that the nonalpha cellulose constituents of different types of fibers vary, weight for weight, in the extent to which they influence deterioration. It is indicated that certain substances such as pentosans are comparatively inert, while the modified celluloses are very active in causing further degradation. It is proposed to study further the relative effects of these different impurities.

3. A considerable amount of preliminary work has been done, indicating that the fluidity in cupra-ammonium solution may offer a ready means of measuring important qualities in paper-making fibers. Further work is planned to correlate such data with data on the strength and permanence qualities of papers.

4. With the results of the investigation of commercial papers and paper-making fibers as a basis, the plan of work will finally include a study of a series of papers prepared in the Bureau of Standards paper mill, in order to establish more conclusively the relative paper-making qualities of the different types of fibers. This work will involve the preparation from each type of material under consideration the best possible quality of paper, in which have been eliminated, as far as possible, most of the variables entering unavoidably into the manufacture of papers at different mills.

5. Before concluding the work on the present series of commercial papers additional samples will be tested for alpha cellulose content, copper number, and acidity. The effect of artificial aging on these properties will also be determined.

\section{SUMMARY AND CONCLUSIONS}

The qualities of purified wood fibers and commercial papers prepared from these fibers have been investigated from the standpoint of chemical purity, color, durability, and permanence.

The data obtained thus far point to the following general conclusions:

1. While it is desirable that the alpha cellulose content of papermaking fibers intended for permanent uses should be as high as possible, conclusions based on this determination alone may be in error due to the fact that the nonalpha cellulose constituents of different types of fibers vary, weight for weight, in the extent to which they influence the permanence qualities of these fibers. Modified celluloses are 
known to be active in causing rapid deterioration of cellulose; pentosans, on the other hand, appear to be relatively inert in this respect.

2. The decrease in the alpha cellulose content of a material, caused by artificial aging, is considered an indication of relative permanence. Purified wood fibers, like purified rag fibers, undergo but slight loss of alpha cellulose after an exposure to an accelerated aging test́ ( $100^{\circ} \mathrm{C}$. for 72 hours).

3. Changes in the alpha cellulose content of papers brought about by artificial aging are accompanied by fairly proportionate changes in physical properties, such as folding endurance and tearing strength.

4. Purified wood fibers, like purified rag fibers, have excellent culor characteristics. Since they are relatively very resistant to the effects of artificial aging, it is indicated that they would show similar good resistance to the yellowing effects of natural aging.

5. A high degree of hydration appears to be detrimental to the permanence of a paper.

6. Inert mineral fillers may be safely added to furnishes for permanent papers and probably aid to some extent in preventing deterioration.

7. The increased strength imparted to papers by glue tub-sizing is rapidly lost on heating, despite the fact that such sizing apparently increases the permanence of papers. Evidently the glue functions as a protective surface, retarding chemical deterioration. Starch, which is also commonly used for the tub-sizing of papers, possibly reacts in a manner similar to glue, but there were not a sufficient number of starch-sized papers included in these tests to permit a definite conclusion in this respect.

8. The manner in which the purified wood fibers, and papers prepared from them, react to the various tests which have been. applied indicates that they are well adapted for use in high-quality. bond and permanent record papers, which have hitherto been made exclusively from furnishes of high-grade rag half stock. It is hoped that the further researches in progress will lead to more definite conclusions in this respect.

Washington, February 16, 1929. 